\title{
Lattice sites of implanted Na in GaN and AIN in comparison to other light alkalis and alkaline earths
}

U. Wahl, ${ }^{1,2, a)}$ E. David-Bosne, ${ }^{2}$ L. M. Amorim, ${ }^{1}$ A. R. G. Costa, ${ }^{2}$ B. De Vries, ${ }^{1}$ J. G. Correia, ${ }^{2}$ M. R. da Silva, ${ }^{3}$ L. M. C. Pereira, ${ }^{1}$ and A. Vantomme ${ }^{1}$

\section{AFFILIATIONS}

${ }^{1}$ KU Leuven, Instituut voor Kern- en Stralingsfysica, 3001 Leuven, Belgium

${ }^{2}$ Centro de Ciências e Tecnologias Nucleares, Departamento de Engenharia e Ciências Nucleares, Instituto Superior Técnico, Universidade de Lisboa, 2695-066 Bobadela LRS, Portugal

${ }^{3}$ CICECO, Institute of Materials, Universidade de Aveiro, 13810-193 Aveiro, Portugal

a) Author to whom correspondence should be addressed: uwahl@ctn.tecnico.ulisboa.pt

\begin{abstract}
The lattice location of ion implanted radioactive ${ }^{24} \mathrm{Na}\left(t_{1 / 2}=14.96 \mathrm{~h}\right)$ in $\mathrm{GaN}$ and AlN was determined using the emission channeling technique at the ISOLDE/CERN facility. In the room temperature as-implanted state in both $\mathrm{GaN}$ and $\mathrm{AlN}$, the majority of the sodium atoms are found on interstitial sites near the octahedral position, with a minority on cation $\mathrm{Ga}$ or $\mathrm{Al}$ substitutional sites. Following annealing at $800-900^{\circ} \mathrm{C}$ the interstitial fraction is reduced while the substitutional incorporation increases. Our results thus further establish the amphoteric character of $\mathrm{Na}$ in GaN and AlN, in analogy to the other light alkali $\mathrm{Li}$, and alkaline earths $\mathrm{Be}$ and $\mathrm{Mg}$. The site changes upon annealing are attributed to the onset of migration of interstitial $\mathrm{Na}$, for which an activation energy of 2.2-3.4 eV is estimated in $\mathrm{GaN}$ and $2.0-3.1 \mathrm{eV}$ in $\mathrm{AlN}$, and its subsequent capture by cation vacancies resulting from the implantation. Comparison of the lattice site change behavior of $\mathrm{Li}, \mathrm{Be}, \mathrm{Na}$ and $\mathrm{Mg}$ shows that the onset of interstitial migration correlates with the ionic radii of these elements.
\end{abstract}

\section{INTRODUCTION}

Due to the widespread applications of GaN and AIN in optoelectronics, the basic properties of some key impurities in these wide band gap semiconductors have been studied quite extensively, e.g. $\mathrm{Mg}$ and $\mathrm{Si}$ as electric dopants, $\mathrm{H}$ as a passivating impurity, to lesser extent also rare earths for optical and transition metals for magnetic doping. For most other elements much less is known. For instance, regarding the properties of sodium, Na implantation was 
found to introduce a broad photoluminescence band around $2.05 \mathrm{eV}$ in GaN already in 1976 [1]. However, since similar bands were observed following the implantation of other elements, this was later considered quite likely a consequence of native defects formed by the implantation damage [2]. Only a limited number of studies on $\mathrm{Na}$ impurities in nitrides were published afterwards, despite the fact that since 1997 liquid phase epitaxy using $\mathrm{Na}$ flux has been used by several groups to produce bulk GaN single crystals [3]. Comparisons of this technique to other $\mathrm{GaN}$ bulk growth methods can be found in a number of reviews [4-8]. In its initial implementation [9] $\mathrm{NaN}_{3}$ was thermally decomposed into liquid $\mathrm{Na}$ and gaseous $\mathrm{N}_{2}$, allowing $\mathrm{N}_{2}$ to react with $\mathrm{Ga}$ dissolved in the liquid $\mathrm{Na}$ and thus resulting in epitaxial growth of $\mathrm{GaN}$ layers on GaN seed crystals. The Na metal was afterwards removed from the surface of the GaN product by reaction with ethanol. In GaN produced with upgraded Na flux techniques, traces of $\mathrm{Na}$ of the order of $4 \times 10^{14} \mathrm{~cm}^{-3}$ were detected [10], although also values around $10^{18} \mathrm{~cm}^{-3}$ have been reported [11]. The potential effects of $\mathrm{Na}$ incorporation in GaN are not well known. For instance, the electrical properties of $\mathrm{Na}$ impurities are expected to depend on their lattice sites and thus also on their ability to form complexes with other defects, e.g. in the form of $\mathrm{Nai}^{+}-\mathrm{Mg}_{\mathrm{Ga}}{ }^{-}$, which would passivate $\mathrm{Mg}$ acceptors.

A first-principles theoretical investigation of the potential acceptor impurities $\mathrm{Li}, \mathrm{Na}, \mathrm{K}, \mathrm{Be}$ and $\mathrm{Mg}$ in $\mathrm{GaN}$ [12] predicted that for the light alkali metals $\mathrm{Na}$ and $\mathrm{Li}$ interstitial $\mathrm{Na}_{\mathrm{i}}$ and $\mathrm{Li}_{\mathrm{i}}$ exhibit lower energies of formation than substitutional NaGa and LiGa as long as the Fermi level is below $\sim 1.2 \mathrm{eV}$ and $\sim 1.7 \mathrm{eV}$, respectively, with respect to the valence band. This means that, in thermodynamic equilibrium, in p-type GaN the incorporation of $\mathrm{Na}$ and $\mathrm{Li}$ impurities on interstitial sites, where they act as single donors, should be more favorable than on the substitutional Ga site, where they represent double acceptors. In contrast, in $n$-type $\mathrm{GaN}$, the predominant $\mathrm{Na}$ and $\mathrm{Li}$ species should be substitutional NaGa and LiGa. The interstitial positions considered by theory were the octahedral $(\mathrm{O})$ and tetrahedral $(\mathrm{T})$ sites, with the octahedral site predicted to be more favorable [12]. As can be seen from Fig. 1, T sites are interstitial sites aligned with the $c$-axis, while $O$ sites are located within the open "channels" of the wurtzite structure parallel to the $c$-axis, both $\mathrm{T}$ and $\mathrm{O}$ sites are located exactly at the center in between planes of $\mathrm{A}$ and $\mathrm{B}$ atoms. A recent theoretical study addressed the detailed positions of interstitial $\mathrm{Mg}, \mathrm{Be}, \mathrm{Li}$, and $\mathrm{Na}$ in $\mathrm{GaN}$, as well as their migration paths and related migration energies [13]. It was predicted that the most stable position for interstitial $\mathrm{Na}^{+}$is " $0.28 \AA$ from ideal octahedral sites". In that respect it must be noted that the definition of ideal $O$ sites in Ref. [13] is different from the one used by us and, 


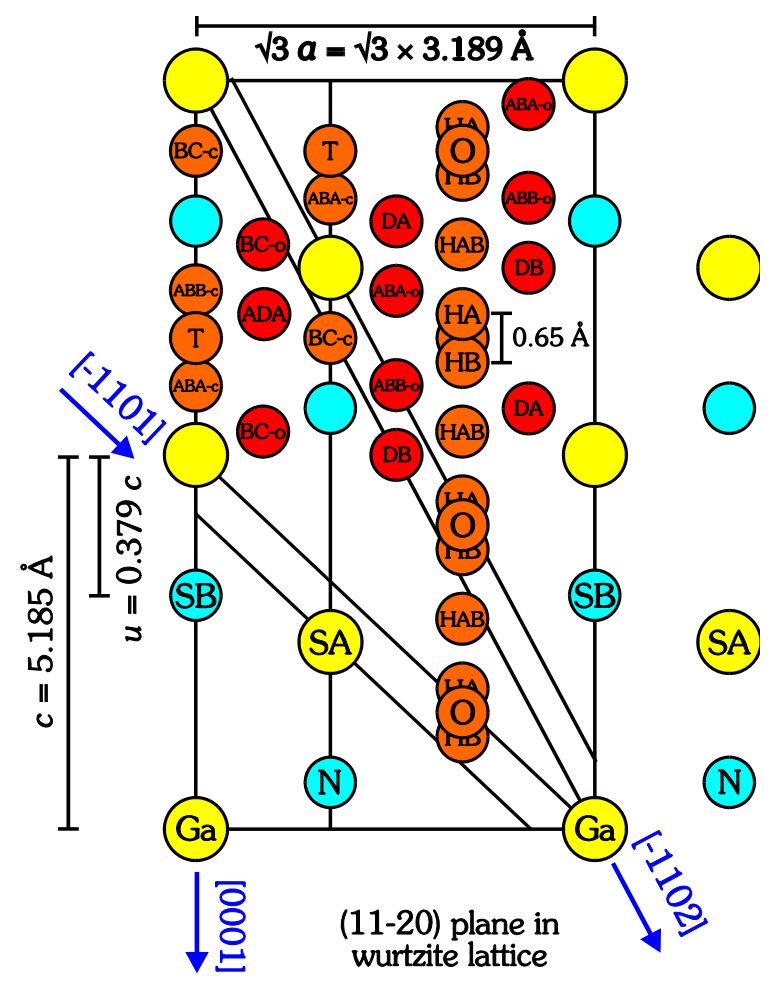

FIG. 1. The (11-20) plane of the GaN wurtzite lattice, showing the substitutional cation $\mathrm{SA}$ (Ga or Al) and anion SB (N) sites, as well as the following interstitial sites: bond center $\mathrm{BC}$, anti-bonding $\mathrm{AB}$, tetrahedral $\mathrm{T}$, symmetric co-planar with Ga-N bonds $\mathrm{D}$ and $\mathrm{AD}$, hexagonal $\mathrm{H}$, and octahedral $\mathrm{O}$. The addition of " $\mathrm{A}$ " or " $\mathrm{B}$ " to the site name indicates nonequivalent sites closer to the cation $\mathrm{A}$ or the anion $\mathrm{B}$, respectively, e.g. the hexagonal sites $\mathrm{HA}$ and HB. On the other hand, the interstitial T, O and HAB sites are defined as having the same distance from A and B sites (i.e. located exactly at the center in between planes of $\mathrm{A}$ and $\mathrm{B}$ atoms). "-c" indicates $\mathrm{BC}$ or $\mathrm{AB}$ sites located within the atomic rows along the c-axis, while those indicated with "-o" are basal to it. The directions around which the $\beta^{-}$ angular emission yield from ${ }^{24} \mathrm{Na}$ was measured are represented by the vectors shown in blue. The values indicated for the lattice constants $a$ and $c$ as well as for the bond length parameter $u$ are those of GaN. A sketch showing the (01-10) plane, which includes the $[-2113]$ axis that was also measured, can be found in the supplementary material.

for instance, Refs [14-15]; the location of the "ideal O site" in Ref. [13] corresponds to our HA site (which is located at $+c / 16=+0.324 \AA$ from $\mathrm{O}$ ). Hence the $\mathrm{Na}^{+}$site coordinate predicted by Ref. [13] is in our nomenclature at $+0.04 \AA$ from O towards HA sites, thus very close to the ideal $\mathrm{O}$ site.

The lattice location of radioactive ${ }^{24} \mathrm{Na}$ implanted in GaN and AlN was investigated by Ronning et al. [16] using the $\beta^{-}$emission channeling technique. Following $30 \mathrm{keV}$ room temperature implantation of ${ }^{24} \mathrm{Na}$ at a fluence of $2 \times 10^{13} \mathrm{~cm}^{-2}$ into GaN and AlN, $\sim 40-44 \%$ of $\mathrm{Na}$ was found aligned with the $c$-axis rows in both cases, while $\sim 56-60 \%$ was located on interstitial sites off the $c$-axis. The interpretation was that all of the $\mathrm{Na}$ that was found aligned 
with the $c$-axis occupied substitutional sites (which could be cation or anion sites), while the interstitial positions off the $c$-axis were assumed to be $\mathrm{O}$ sites, although no definite proof could be given. Only experimental channeling patterns around the [0001] axis were compared to simulated yields for different lattice sites; [-1101] patterns were measured but not analyzed in detail. However, for assessing exact positions along the $c$-axis or parallel to it, which is required for instance in order to properly distinguish between the cation and anion substitutional sites and the interstitial $\mathrm{T}$ sites, or in order to quantify the displacement from interstitial $\mathrm{O}$ sites parallel to the $c$-axis, the analysis of patterns off the $c$-axis is required. The exact locations of substitutional and interstitial $\mathrm{Na}$ could hence not be pinpointed in Ref. [16]. Annealing at $800^{\circ} \mathrm{C}$ for $10 \mathrm{~min}$ was reported to relocate part of the interstitial $\mathrm{Na}$ to sites aligned with the $c$-axis in AlN, while the same treatment seemed to have no effect on ${ }^{24} \mathrm{Na}$ in GaN.

In this article we report on detailed measurements of the lattice location of implanted ${ }^{24} \mathrm{Na}$ in $\mathrm{GaN}$ and $\mathrm{AlN}$, in the room temperature (RT) as-implanted state and for annealing temperatures up to $900^{\circ} \mathrm{C}$. In addition to [0001] (c-axis) emission channeling patterns, also $[-1102],[-1101]$, and [-2113] directions off the $c$-axis were measured. Fitting all the experimentally observed electron yield distributions to theoretical patterns calculated for a variety of lattice sites, aligned and off the $c$-axis, allowed determining the location of interstitial $\mathrm{Na}$ within $\sim 0.2 \AA$. Moreover, lattice site changes of $\mathrm{Na}$ from interstitial to substitutional sites that were observed following annealing in both GaN and AlN, allowed deriving estimates for the $\mathrm{Na}$ interstitial migration energies. Finally, we compare the lattice location preference of $\mathrm{Na}$ and its interstitial diffusion characteristics to the corresponding properties of $\mathrm{Li}, \mathrm{Mg}$, and $\mathrm{Be}$, pointing out qualitative similarities and systematic quantitative differences.

\section{METHODS}

$\beta^{-}$emission channeling is a nuclear technique that allows measuring the lattice location of radioactive impurities implanted in a single-crystal [17-19]. The $\beta^{-}$particles emitted during the decay of radioactive probe atoms travel inside the crystal with enough energy to perceive the nuclei arranged along axes and planes as a positive continuum potential that is formed by the average of individual, screened Coulomb potentials. Thus, in a simplified view, the negatively charged $\beta^{-}$particles that are emitted from sites that are aligned with high symmetry axes or planes of the crystal, e.g. from substitutional sites, are channeled if the 
emission occurred within certain critical angles, while those emitted above the critical angle are scattered randomly. On the other hand, emission from interstitial sites that are not aligned with crystallographic axes or planes generally leads to enhanced scattering along these directions. Using a two-dimensional position-sensitive detector (PSD) which is successively oriented with the major axial directions of the crystal, the angular emission yield around these axes is measured, which is characteristic of the probe atom lattice location in the sample. The two-dimensional angular emission yields are fitted with linear combinations of simulated patterns of emitter atoms on different lattice sites.

TABLE I. Samples, implantation and measurement parameters. All samples were implanted at RT and measured in the as-implanted state and following 10 min annealing under vacuum at the indicated temperatures TA. See Ref [29] for additional sample properties.

\begin{tabular}{|l|l|l|l|}
\hline Sample & GaN \#1 & GaN \#2 & AlN \\
\hline Growth method & MOVPE (U Cambridge) & MOVPE (Cree Inc.) & MOVPE (U Montpellier) \\
\hline $\begin{array}{l}\text { Film thickness } \\
(\mu \mathrm{m})\end{array}$ & 4.8 & 1.75 & 0.28 \\
\hline $\begin{array}{l}\text { Implantation } \\
\text { energy }(\mathrm{keV})\end{array}$ & 40 & 50 & 60 \\
\hline $\begin{array}{l}\text { Implantation angle } \\
\left({ }^{\circ}\right)\end{array}$ & 17 & 10 & 10 \\
\hline Fluence $\left(\mathrm{cm}^{-2}\right)$ & $2.9 \times 10^{13}$ & $4.8 \times 10^{12}$ & $5.3 \times 10^{12}$ \\
\hline Projected range $(\AA)$ & 422 & 535 & 825 \\
\hline Straggling $(\AA)$ & 209 & 257 & 300 \\
\hline$\left.{ }^{24} \mathrm{Na}\right]_{\text {peak }}\left(\mathrm{cm}^{-3}\right)$ & $4.9 \times 10^{18}$ & $6.2 \times 10^{17}$ & $6.9 \times 10^{17}$ \\
$(55 \mathrm{ppm})$ & $(7 \mathrm{ppm})$ & $(7 \mathrm{ppm})$ \\
\hline$T_{\mathrm{A}}\left({ }^{\circ} \mathrm{C}\right)$ & 800 & 900 & 600,900 \\
\hline Detector & pad + Timepix & pad & pad \\
\hline
\end{tabular}

For lattice location of $\mathrm{Na}$, we made use of the same radioactive isotope ${ }^{24} \mathrm{Na}\left(t_{1 / 2}=14.96 \mathrm{~h}\right)$ as in Ref. [16]. The production of ${ }^{24} \mathrm{Na}$ at the on-line isotope separator facility ISOLDE/CERN [20] as well as its relevant decay characteristics have been outlined in our previous publication on the lattice location of ${ }^{24} \mathrm{Na}$ in $\mathrm{ZnO}$ [21]. The experimental setup is described in Ref. [22]. All samples were measured using Si pad PSDs consisting of $22 \times 22$ pixels of size $1.3 \mathrm{~mm}$, our standard systems for electron emission channeling studies [23]. The GaN sample \#1 (cf. Table I) was in addition studied with a new, highly pixelated quad Timepix PSD 
consisting of $512 \times 512$ pixels of $55 \mu \mathrm{m}$ size [24-25], thus allowing to compare the results from two different measurement and analysis methods. Both detectors were mounted at a distance of $30 \mathrm{~cm}$ from the sample, leading to angular resolutions of $0.081^{\circ}$ (standard deviation) for the pad geometry and $0.050^{\circ}$ for the Timepix. Note that for the pad detector the size of the $1 \mathrm{~mm}$ diameter beam spot on the sample and the detector pixel size of $1.3 \mathrm{~mm}$ contribute with comparable magnitude to the angular resolution, while for the Timepix detector, the angular resolution is dominated by the beam spot dimension [26].

The "many-beam" theoretical approach for calculating electron emission channeling patterns from emitter atoms on different lattice sites has been discussed in Refs [17-18] and input parameters for the structural models of GaN and AlN are given in Refs [27-28]. The fit routines for comparing experimental and theoretical data were outlined in Refs [18, 23] and recently described in detail in Ref. [26]. For fitting the results obtained with the pad detector we used our proprietary software FDD, while Timepix patterns were fitted using the newly developed PyFDD code, in both cases using chi square minimization [26]. The fitted fractions were corrected for background from scattered electrons and from gammas, as is explained in more detail in Refs [21, 29].

Three samples (two GaN and one AlN, all not intentionally doped) were implanted using the parameters given in Table I, with beam spots of $1 \mathrm{~mm}$ diameter. While the $\mathrm{GaN}$ samples were 1.5 and $4.8 \mu \mathrm{m}$ thick layers grown on sapphire, the AlN sample [30] consisted of a $0.28 \mu \mathrm{m}$ AlN thin film with a $0.55 \mu \mathrm{m} \mathrm{Al} 0.2 \mathrm{Ga} 0.8 \mathrm{~N}$ buffer layer on a sapphire substrate. It is known that AlN films are subject to suffer from more structural imperfections and mosaicity than GaN. Hence the tilt and twist values of the mosaic domain distributions for this AlN sample were determined by means of $X$ ray diffraction using the method of Srikant et al. [31-33], and values of $W_{\text {tilt }}=0.20^{\circ}$ and $W_{\text {twist }}=0.56^{\circ}$ were found [29] (in contrast, typical values for GaN

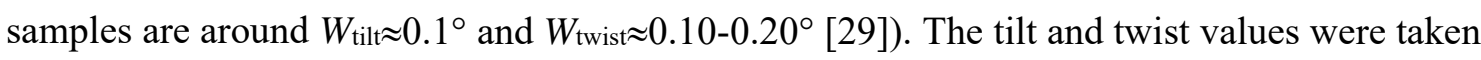
into account by adjusting the angular resolution of the theoretical patterns used for the fits, as described in Ref. [32]. The angular emission yields in the vicinity of the four high-symmetry directions [0001], [-1102], [-1101] and [-2113]) were measured at RT, both in the asimplanted state and following 10 min vacuum annealing steps as indicated in Table I. 


\section{RESULTS}

\section{A. Best fit patterns}

The experimental emission channeling patterns measured as-implanted in GaN with the pad detector are plotted in Fig. 2(a)-(d). Simulated patterns resulting from ${ }^{24} \mathrm{Na}$ radioactive probes in GaN on a number of different lattice sites are shown in the supplementary material. While the yield maximum measured along the [0001] axis [in the center of Fig 2(a)] is a characteristic of probes on substitutional (S) or tetrahedral (T) interstitial sites, which are all aligned with the $c$-axis, the planar emission yields in the same pattern show major channeling effects only along the set of three (11-20) planes, while the channeling yields from the set of three (01-10) planes are considerably reduced. In the wurtzite structure this combination of planar effects is a strong indication that, besides sites aligned with the $c$-axis, also a large fraction of probe atoms occupies sites in the wide open interstitial region of the lattice parallel to the $c$-axis [21]. This is further evidenced by the characteristics of the [-2113] pattern: while substitutional ${ }^{24} \mathrm{Na}$ alone would create strong (01-10) planar channeling along the "horizontal plane" in Fig. 2(d), ${ }^{24} \mathrm{Na}$ near the interstitial $\mathrm{O}$ sites results in "blocking" along the same plane. In the case of $[-1102]$ and $[-1101]$ directions the distinction between octahedral interstitial and substitutional ${ }^{24} \mathrm{Na}$ is not immediately obvious since the $\mathrm{O}$ sites are approximately aligned with these axial directions (cf. Fig. 1). The results of fitting a linear combination of theoretical patterns from ${ }^{24} \mathrm{Na}$ probes on two different lattice sites fully confirmed the qualitative arguments outlined above: the best fits [Fig. 2(e)-(h)] were obtained for fractions of $38(4) \%$ of ${ }^{24} \mathrm{Na}$ on $\mathrm{S}_{\mathrm{Ga}}$ and $45(8) \%$ very close to the octahedral interstitial $\mathrm{O}$ sites. The difference of the sum of the two fractions from $100 \%$ is assigned to the so-called "random" fraction, that results from a flat background in the patterns and e.g. includes probe atoms in sites of very low crystal symmetry [26]. Note that the positions of the interstitial $\mathrm{Nai}_{\mathrm{i}}$ sites parallel to the $c$-axis used for Fig. 2(e)-(h) were identified as described below in section B. 
GaN RT experiment simulation $45 \% \mathrm{Na}_{\mathrm{i}}+38 \% \mathrm{~S}_{\mathrm{Ga}}$ sites
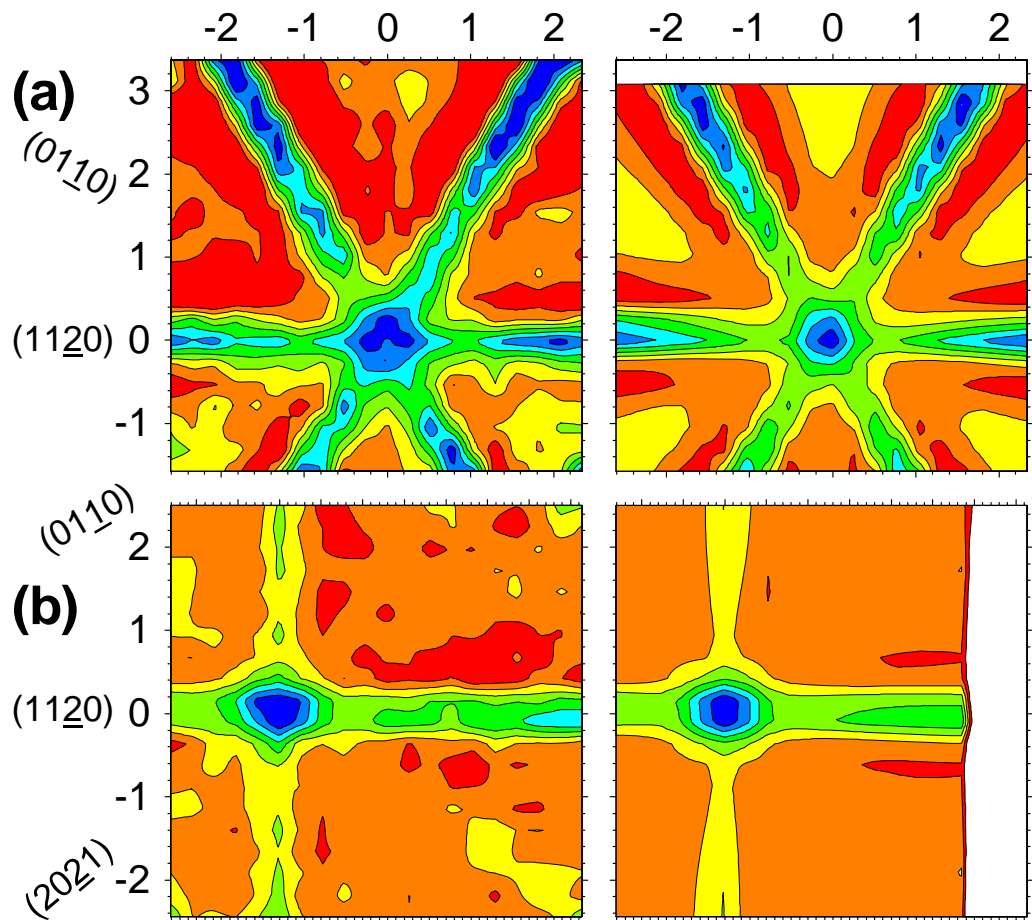

(e) [0001]

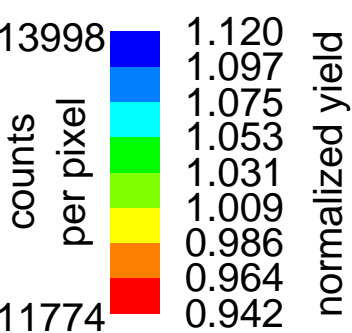

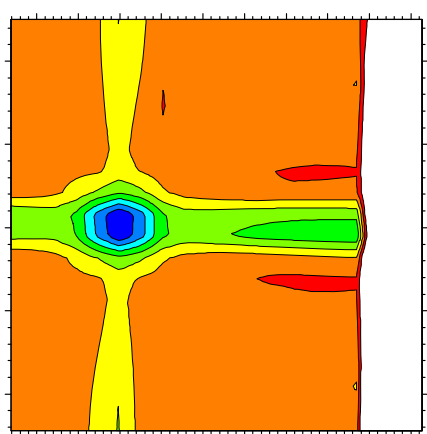

(f) [1102]

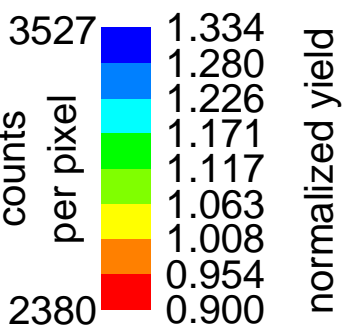
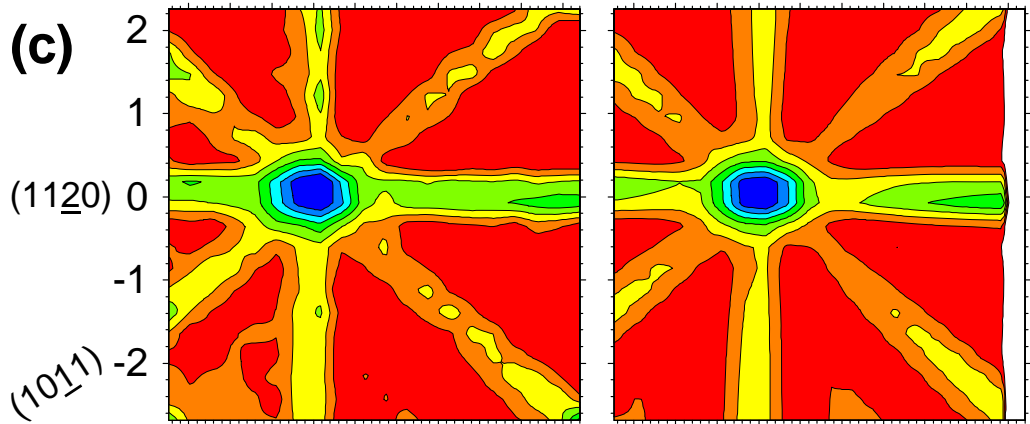

(g) [1101]
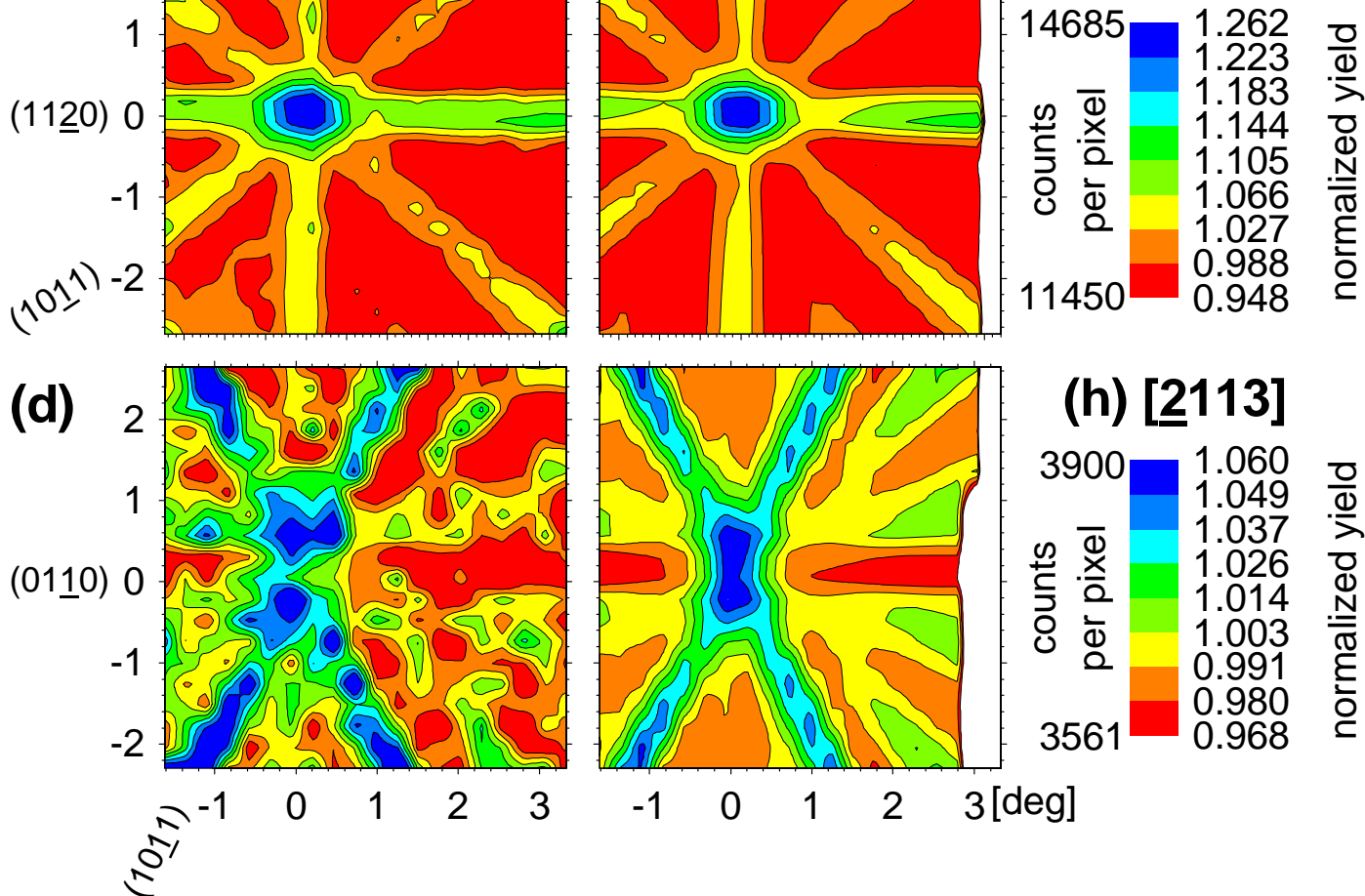

FIG. 2. (a)-(d) Angular distribution of $\beta^{-}$emission yields from ${ }^{24} \mathrm{Na}$ in $\mathrm{GaN}$ sample $\# 1$, measured as-implanted at RT with the pad detector. Patterns are shown as contour plots around the [0001], $[-1102],[-1101]$ and $[-2113]$ axes, with the color scales indicating both number of counts per pixel and the normalized yields. The approximate numbers of events measured were $6.0 \times 10^{6}(\mathrm{a}), 1.6 \times 10^{6}(\mathrm{~b}), 6.9 \times 10^{6}(\mathrm{c})$, and $2.1 \times 10^{6}(\mathrm{~d})$. (e)-(h): the best fit of simulated patterns, corresponding to $45(8) \%$ on $\mathrm{Na}_{\mathrm{i}}$ interstitial and $38(4) \%$ on $\mathrm{S}_{\mathrm{Ga}}$ sites. 
GaN $T_{A}=800^{\circ} \mathbf{C}$ experiment simulation $17 \% \mathrm{Na}_{\mathrm{i}}+54 \% \mathrm{~S}_{\mathrm{Ga}}$ sites
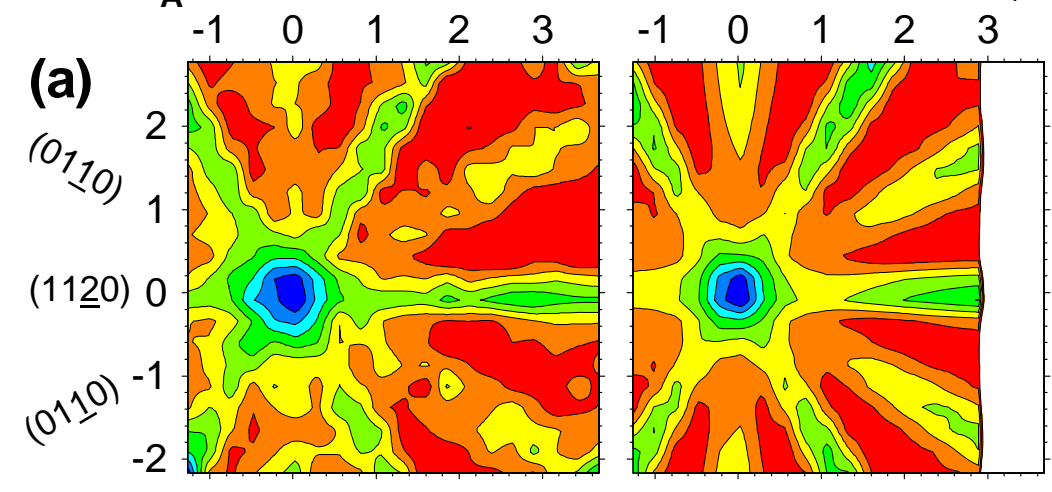

(e) [0001]

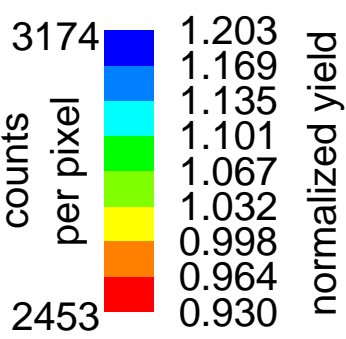
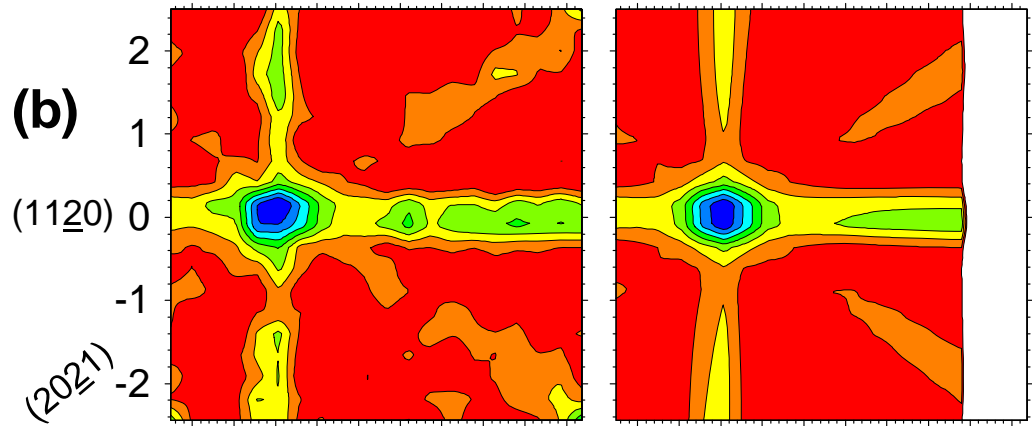

(f) [1102]

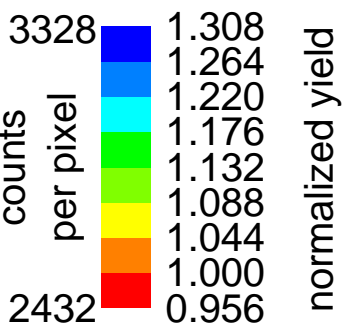
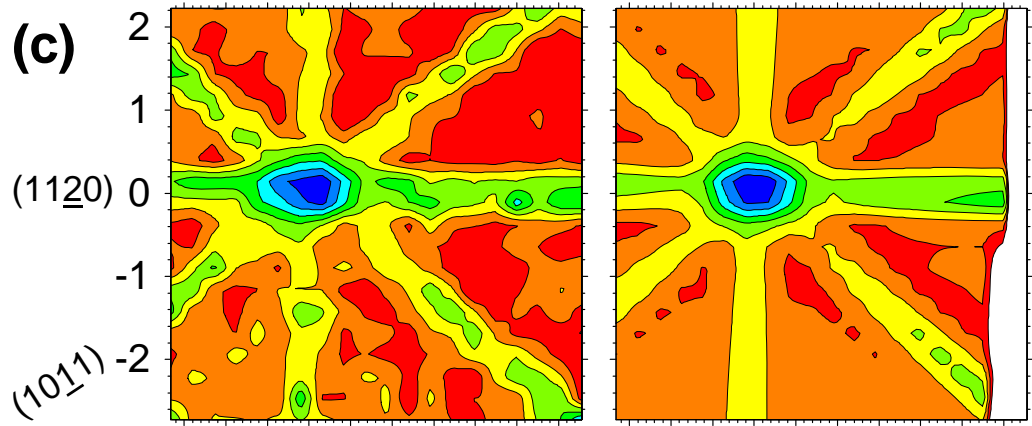

(g) [1101]
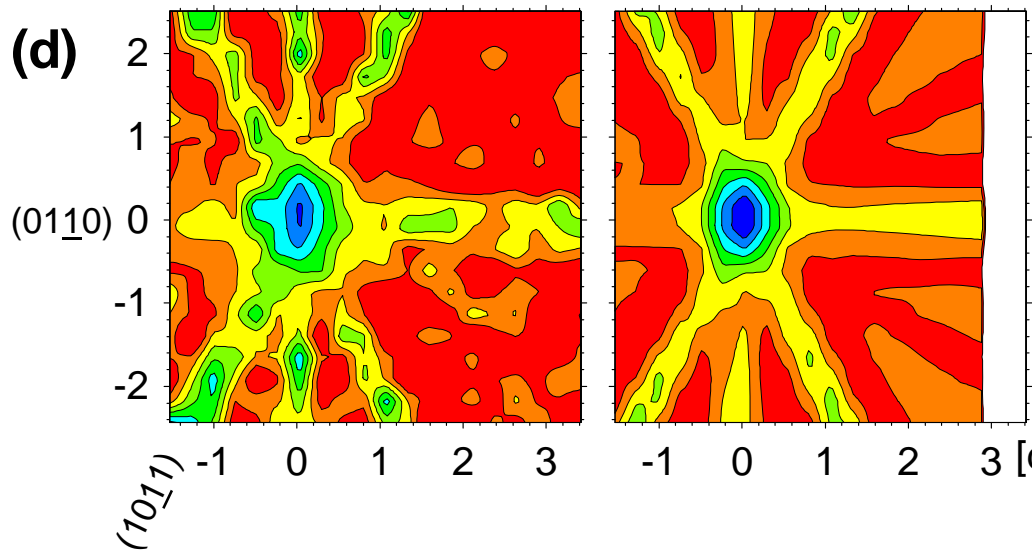

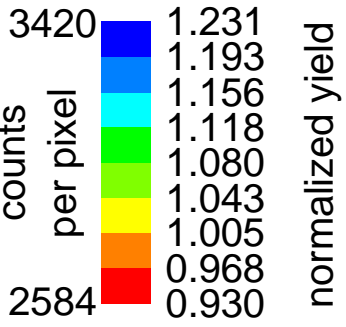

(h) [2113]

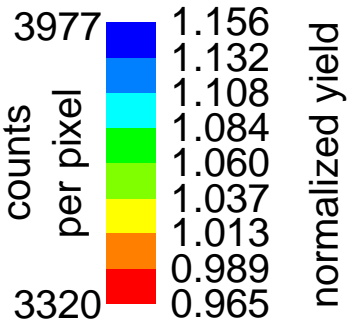

FIG. 3. Same as Fig. 2 but measured following annealing at $T_{\mathrm{A}}=800^{\circ} \mathrm{C}$. (a)-(d) are experimental patterns while (e)-(h) show the best fit of simulated patterns, corresponding to $17(2) \%$ on $\mathrm{Na}_{\mathrm{i}}$ interstitial and $54(5) \%$ on $\mathrm{S}_{\mathrm{Ga}}$ sites. The approximate numbers of events measured were $2.0 \times 10^{6}(\mathrm{a}), 1.5 \times 10^{6}(\mathrm{~b}), 1.3 \times 10^{6}(\mathrm{c})$, and $1.3 \times 10^{6}(\mathrm{~d})$. 
Following $800^{\circ} \mathrm{C}$ annealing, several features in the measured patterns changed [Fig. 3(a)-(d)]. In the [0001] pattern [Fig. 3(a)], the axial channeling effect almost doubled in intensity, and channeling effects from both (11-20) and (01-10) planes are now clearly visible. In the [-2113] pattern, the axial channeling effect, which was characterized in the as-implanted state by a double peak of low intensity, turned into a much stronger single peak, at the same time the (01-10) plane changed from blocking to channeling. These qualitative arguments indicate that interstitial ${ }^{24} \mathrm{Na}$ was converted to substitutional, which was confirmed by the best fits [Fig. 3(e)-(h)], which were obtained for fractions of 54(5)\% of ${ }^{24} \mathrm{Na}$ on $\mathrm{S}_{\mathrm{Ga}}$ and only $17(2) \%$ on the octahedral interstitial $\mathrm{O}$ sites. The experimental results and best fit patterns measured for the same sample GaN \#1 with the Timepix detector and for GaN \#2 with a pad detector can be found in the supplementary material [29].

The patterns measured for ${ }^{24} \mathrm{Na}$ in AlN are shown in Fig. 4(a)-(d) in the as-implanted state and in Fig. 5(a)-(d) following the last annealing step at $900^{\circ} \mathrm{C}$. Due to the lower structural quality of the AlN sample, but also a number of other reasons [29], the patterns show less contrast than GaN. However, the axial and planar features that allow distinguishing the preference for interstitial sites of ${ }^{24} \mathrm{Na}$ in the as-implanted state and for substitutional $\mathrm{Al}$ sites following annealing, are also present. The best fits were obtained for $49(15) \%$ on $\mathrm{Na}_{\mathrm{i}}$ interstitial and $35(6) \%$ on $\mathrm{S}_{\mathrm{Al}}$ sites as-implanted [Fig. 4(e)-(h)], and $16(10) \%$ on $\mathrm{Na}_{\mathrm{i}}$ interstitial and $65(8) \%$ on $\mathrm{S}_{\mathrm{Al}}$ sites following $T_{\mathrm{A}}=900^{\circ} \mathrm{C}$ [Fig. 5(e)-(h)]. 
AIN RT experiment simulation $49 \% \mathrm{Na}_{\mathrm{i}}+35 \% \mathrm{~S}_{\mathrm{Al}}$ sites
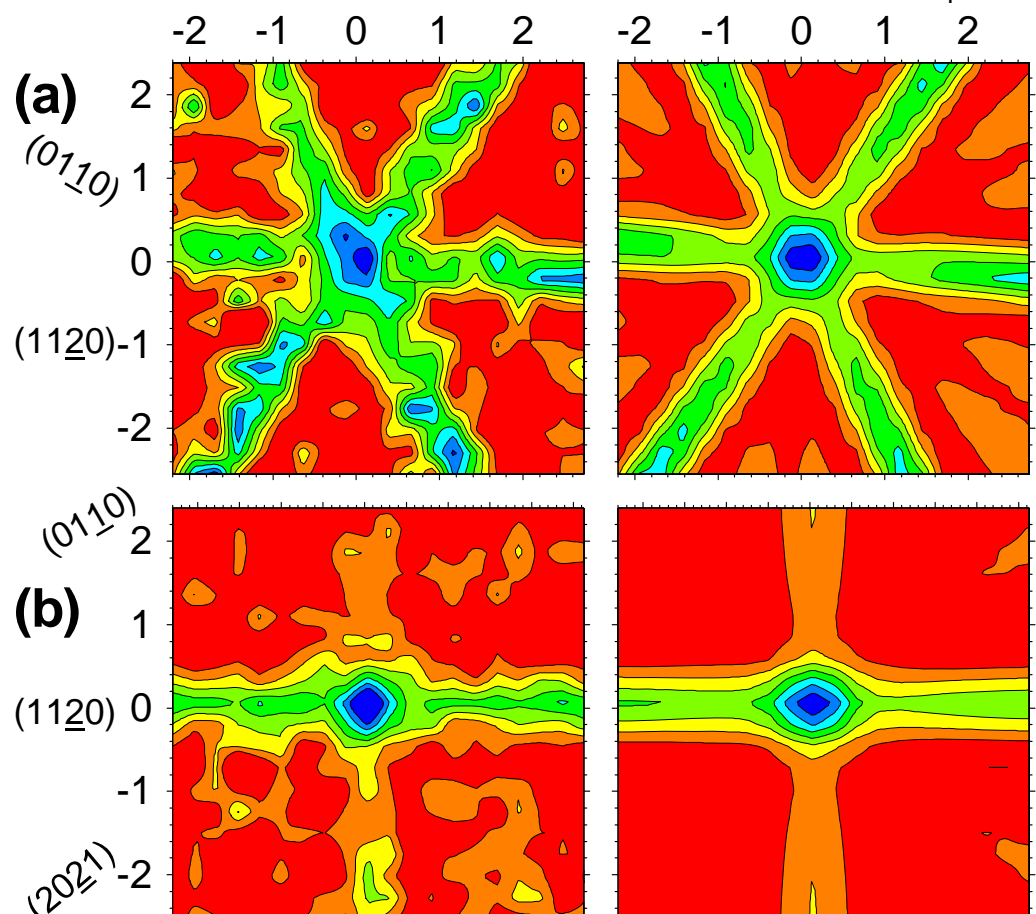

(e) [0001]

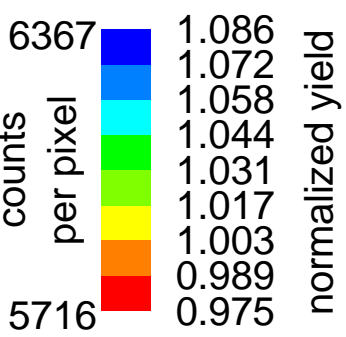

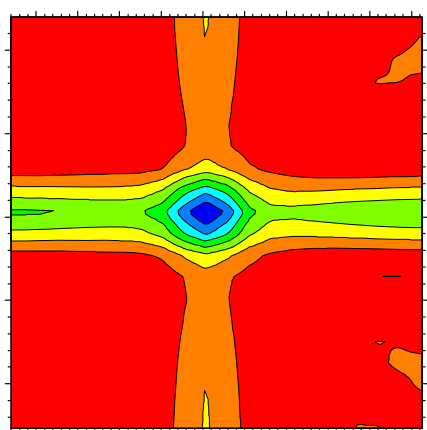

(f) [1102]

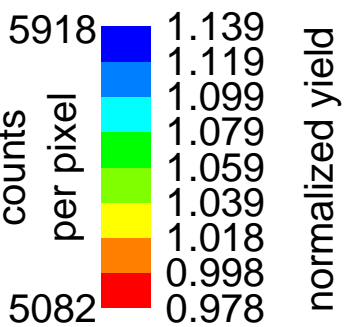
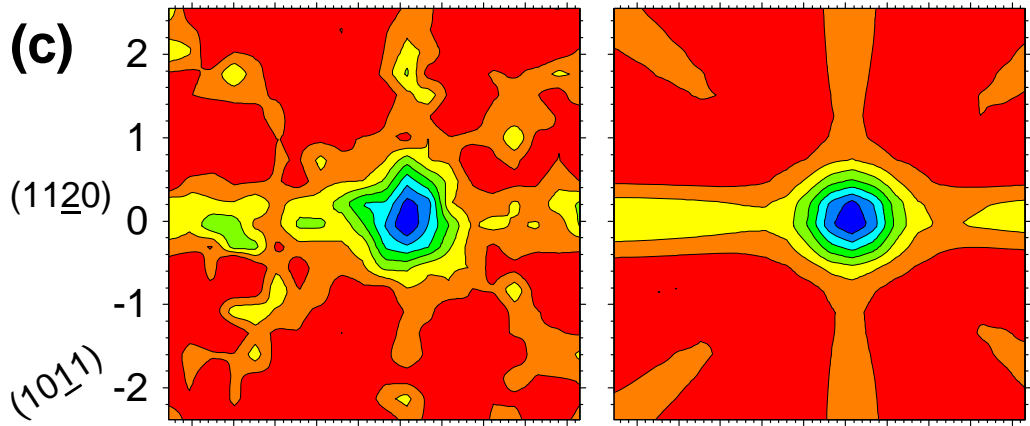

(g) [1101]

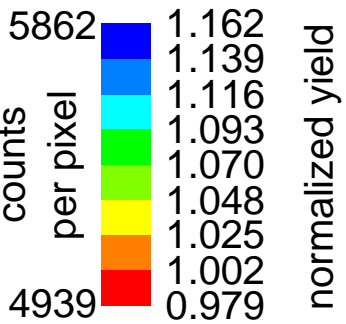
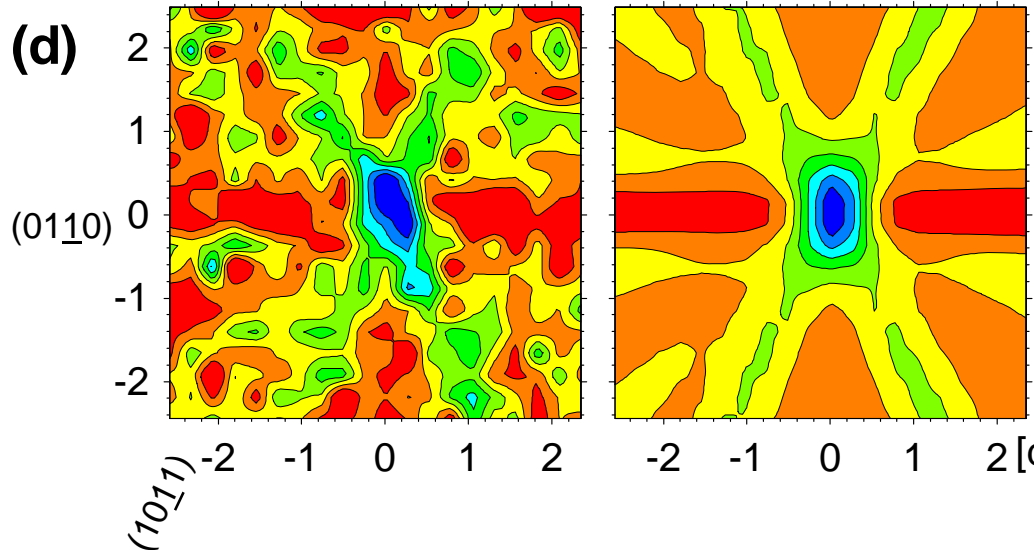

(h) [2113]

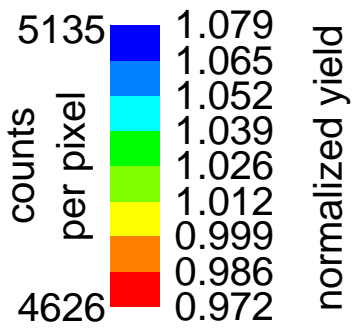

FIG. 4. (a)-(d) Angular distribution of $\beta^{-}$emission yields from ${ }^{24} \mathrm{Na}$ in $\mathrm{AlN}$, measured asimplanted at RT with the pad detector. Patterns are shown as contour plots around the [0001], [-1102], [-1101] and [-2113] axes. The approximate numbers of events measured were $3.2 \times 10^{6}(\mathrm{a}), 2.9 \times 10^{6}(\mathrm{~b}), 2.9 \times 10^{6}(\mathrm{c})$ and $2.7 \times 10^{6}(\mathrm{~d})$. (e)-(h): the best fit of simulated patterns, corresponding to $49(15) \%$ on Nai interstitial and $35(6) \%$ on $\mathrm{S}_{\mathrm{Al}}$ sites. 
AIN $T_{A}=900^{\circ} \mathrm{C}$ experiment simulation $16 \% \mathrm{Na}_{\mathrm{i}}+65 \% \mathrm{~S}_{\mathrm{Al}}$ sites

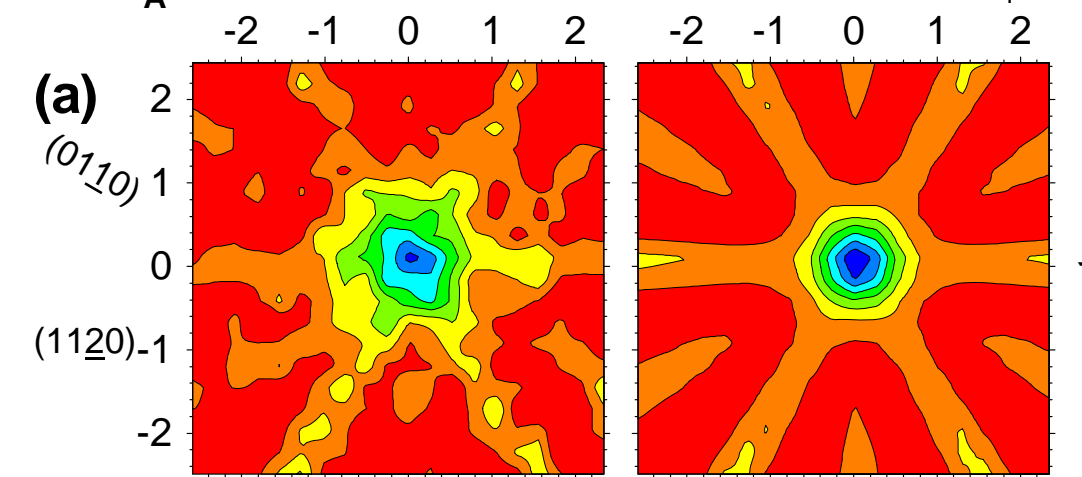

(e) [0001]

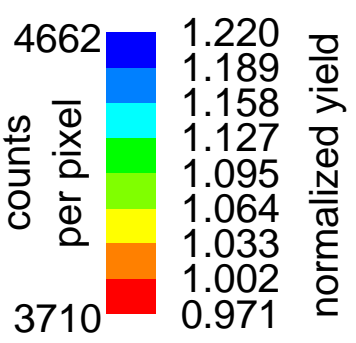
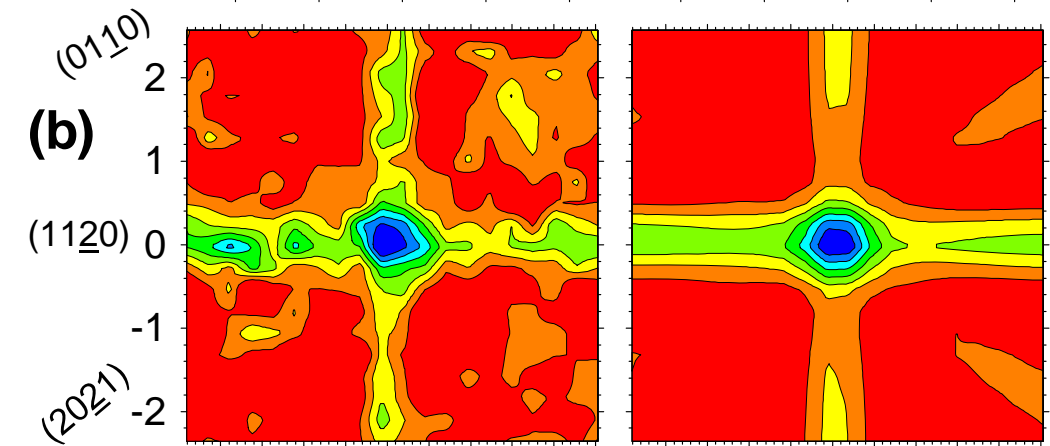

(f) [1102]
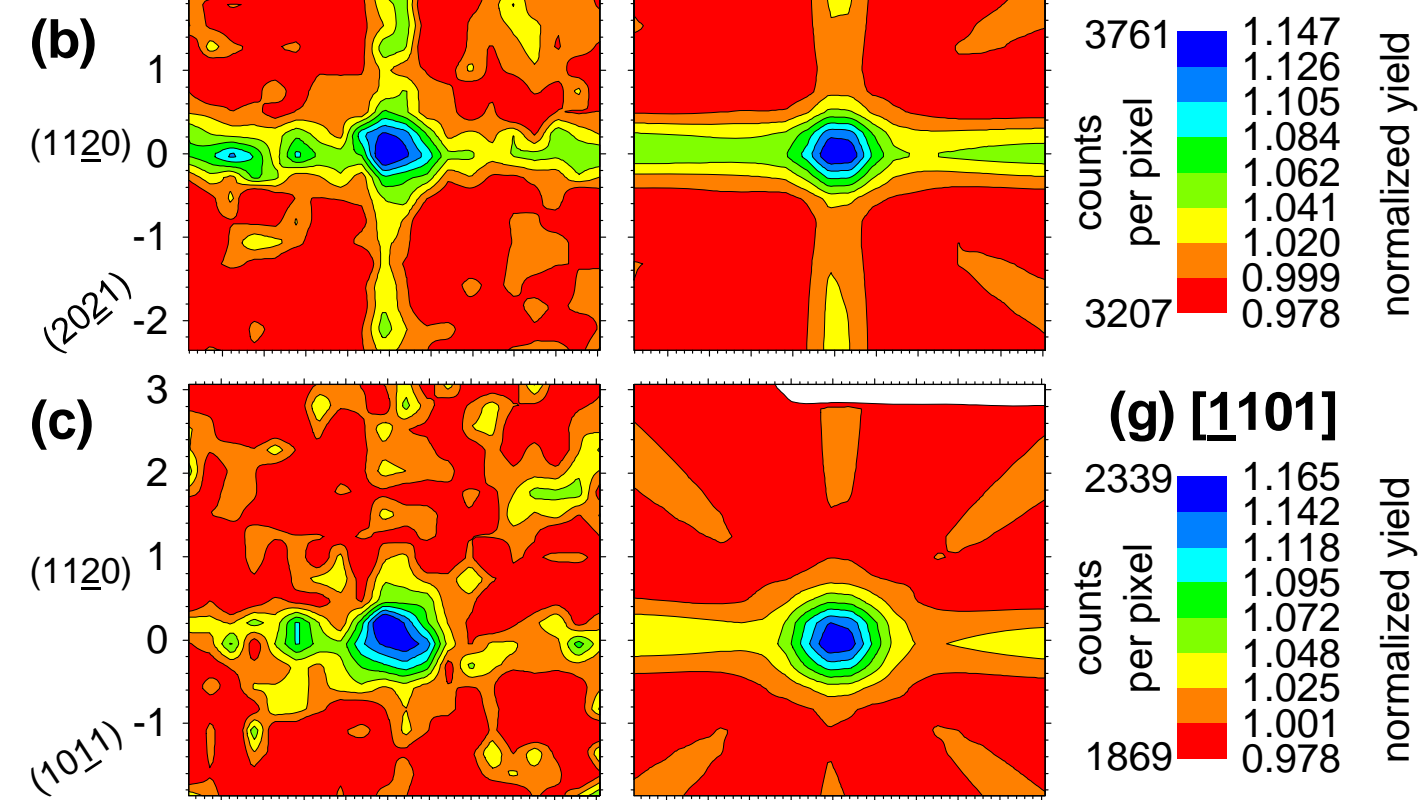

(g) [1101]

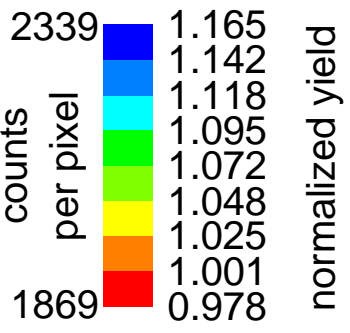
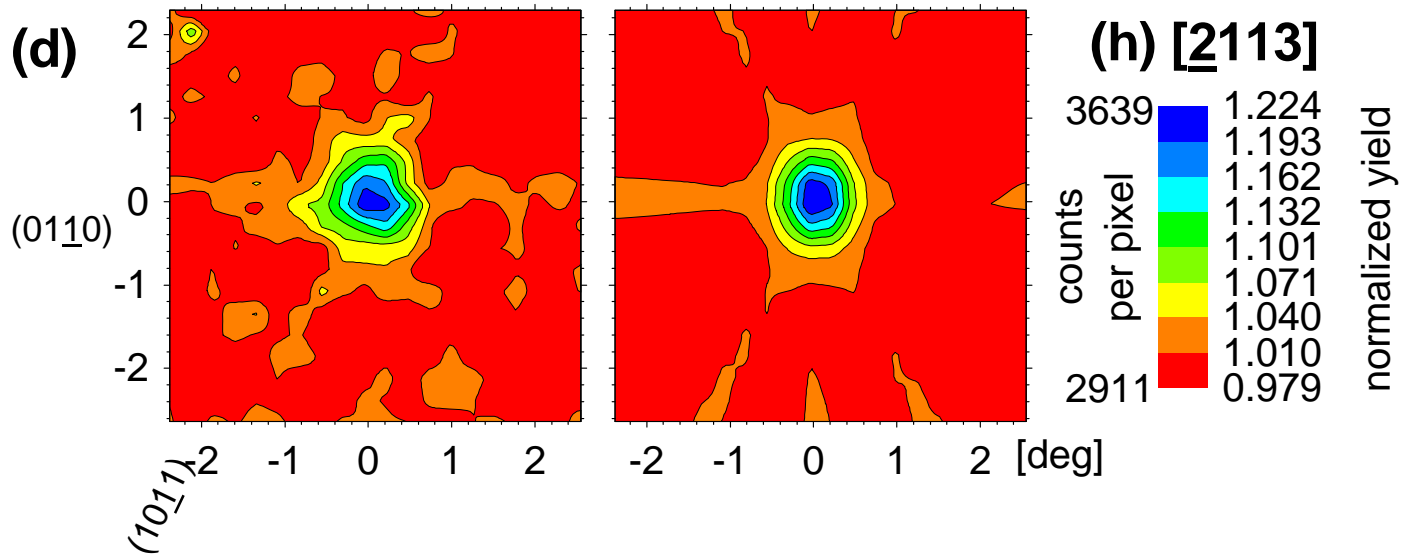

FIG. 5. Same as Fig 4 but measured following annealing at $T_{\mathrm{A}}=900^{\circ} \mathrm{C}$. (a)-(d) are experimental patterns while (e)-(h) show the best fit of simulated patterns, corresponding to $16(10) \%$ on Nai interstitial and $65(8) \%$ on $\mathrm{S}_{\mathrm{Al}}$ sites. The approximate numbers of events measured were $2.4 \times 10^{6}(\mathrm{a}), 2.2 \times 10^{6}(\mathrm{~b}), 2.0 \times 10^{6}(\mathrm{c})$ and $2.6 \times 10^{6}(\mathrm{~d})$. 


\section{B. Positions of $\mathrm{Na}_{\mathrm{i}}$ interstitial sites}

In order to determine as accurately as possible the most probable positions of interstitial ${ }^{24} \mathrm{Na}$ parallel to the $c$-axis, i.e. to distinguish between the octahedral $(\mathrm{O})$ and various hexagonal interstititial sites (HA, HB and HAB), schematically shown in Fig. 1, we have applied the following procedure to the $[-1102],[-1101]$ and [-2113] patterns (channeling effects measured along [0001] are not sensitive to displacements parallel to the $c$-axis). Note that in contrast to our former publications $[19,21,26,28,34]$, we have now adopted that displacements from $\mathrm{O}$ to $\mathrm{HB}$ sites are represented by a positive coordinate, since they occur along the $+c$-axis [0001] (cf. Figs 1, 6 and 7), while displacements from $O$ to HA are associated with negative coordinates, since they occur along $-c$-axis [000-1]. This was chosen so as to be in line with the convention used in other publications, e.g. [13-15]. In Figs 6 and 7 the relative $\chi^{2}$ is plotted for two-site fits where the position of the first site is kept fixed at the ideal substitutional Ga or Al site, while the position of the second site is varied parallel to the $c$-axis in small steps of $0.016 \AA$ from $\mathrm{O}$ to $\mathrm{HA}$ or $\mathrm{HB}$, and $0.049 \AA$ from $\mathrm{HA}$ to $\mathrm{HAB}$ and $\mathrm{HB}$ to HAB. Note that $\chi^{2}$ is given relative to one-site fits that include only the ideal substitutional site. For as-implanted ${ }^{24} \mathrm{Na}$ in GaN sample \#1 (red curves in Fig. 6) the relative $\chi^{2}$ for the [-1102], [-1101] and [-2113] pad detector pattern fits shows minima for interstitial sites which are displaced by $+0.032 \AA,+0.049 \AA$, and $-0.032 \AA$ from ideal $O$ sites, with the average of the three derived displacements being $+0.016 \AA$, i.e. very close to the ideal $\mathrm{O}$ sites. The identical type of analysis performed for the patterns measured for the same sample \#1 with the Timepix detector (magenta curves in Fig. 6), yields displacements of $+0.016 \AA,-0.016 \AA$, and $-0.049 \AA$ from ideal $\mathrm{O}$ sites, average value $-0.016 \AA$. The two separate measurement and analysis procedures hence agree on the result that interstitial ${ }^{24} \mathrm{Na}$ is found very close to ideal $\mathrm{O}$ sites in sample \#1. However, the same kind of analysis showed somewhat different results for the GaN sample \#2 (blue curves in Fig. 6), the relative $\chi^{2}$ for the [-1102], [-1101] and [-2113] pattern fits shows minima for $\mathrm{Na}_{\mathrm{i}}$ interstitial sites displaced $-0.194 \AA,-0.162 \AA$, and $-0.194 \AA$ from ideal O sites, with the average being $-0.184 \AA$, hence closer to HA than to $O$ sites. Following annealing, the variations in $\chi^{2}$ are much less pronounced for both GaN samples, also the spreads in between the minima of the best fit positions become larger, both due to the fact that the fractions of interstitial ${ }^{24} \mathrm{Na}$ are considerably reduced, causing the statistical relevance of the results to be less significant and the assessment of the $\mathrm{Na}_{\mathrm{i}}$ interstitial position to be less precise. 


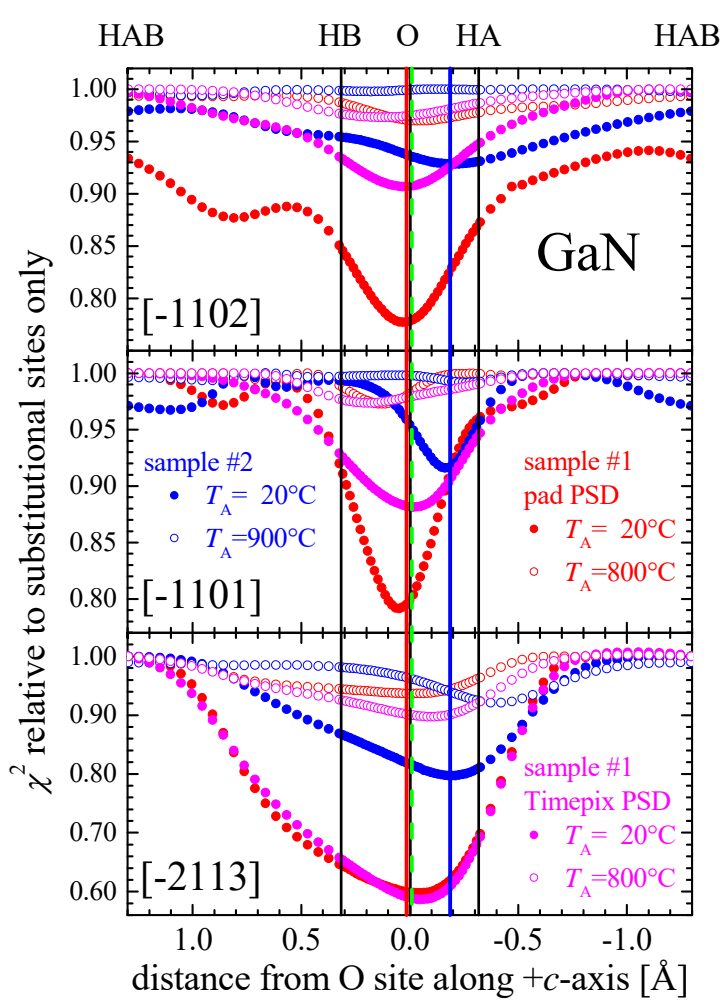

FIG. 6. Relative $\chi^{2}$ of the fits to the experimental [-1102], [-1101], [-2113] patterns from ${ }^{24} \mathrm{Na}$ in $\mathrm{GaN}$ as function of displacement of the ${ }^{24} \mathrm{Na}$ atoms from the ideal interstitial $\mathrm{O}$ sites parallel to the c-axis. Each data point corresponds to the $\chi^{2}$ of the best fit obtained using two given sites, with the corresponding two fractions as free parameters. The site pairs are composed of a fixed $\mathrm{S}_{\mathrm{Ga}}$ site plus a second site, which is shifted from the ideal interstitial $\mathrm{O}$ site along the c-axis. The relative $\chi^{2}$ values were normalized to that of the one-site $\mathrm{S}_{\mathrm{Ga}}$ fit. The black vertical lines indicate the positions of the HB, O and HA interstitial sites. The dashed green line is the theoretically predicted position of $\mathrm{Na}_{i}^{+}$in $\mathrm{GaN}$ from Ref. [13], which practically coincides with the $\mathrm{O}$ site. The red vertical line shows the average of the best fit positions from sample \#1, while the blue vertical line shows the average from sample $\# 2$, both in the as-implanted state.

In case of AlN the relative $\chi^{2}$ for the [-1102], [-1101] and [-2113] pattern fits (Fig. 7) shows minima for interstitial sites displaced $-0.063 \AA,-0.095 \AA$, and $-0.221 \AA$ from ideal O sites, with the average being $-0.126 \AA$. Overall, the relative changes in $\chi^{2}$ as a function of the position of the interstitial $\mathrm{Na}_{i}$ site are less pronounced in AlN than in $\mathrm{GaN}$. We attribute this to the larger mosaic spread of the AlN film, which effectively lowers the angular resolution of the channeling measurements and hence also diminishes the ability to distinguish different lattice sites. 


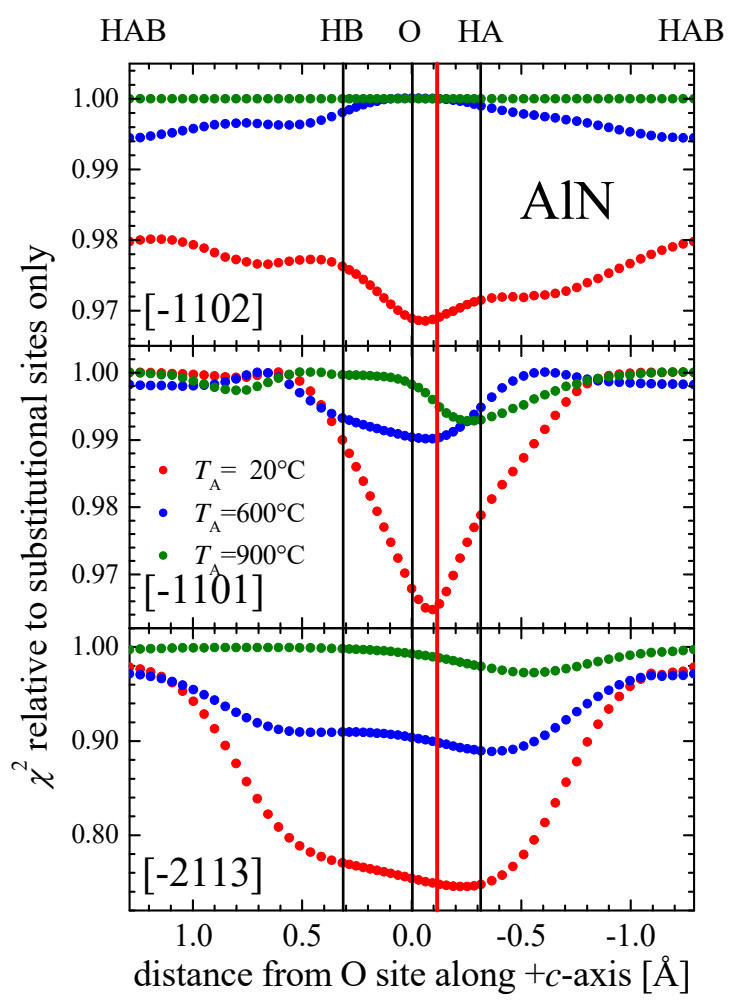

FIG. 7. Relative $\chi^{2}$ of the fits as function of ${ }^{24} \mathrm{Na}$ displacement from the ideal interstitial $\mathrm{O}$ sites parallel to the c-axis in AlN. Normalization is as described in the caption of Fig. 8. The red vertical line shows the average of the best fit positions in the as-implanted state. The [-1102] fits following $T_{\mathrm{A}}=600^{\circ} \mathrm{C}$ did not result in chi square minima consistent with the other directions, and following annealing at $T_{\mathrm{A}}=900^{\circ} \mathrm{C}$ yielded negative interstitial fractions (which we have represented by the straight line at 1.0). In both cases chi square changes were so small that [-1102] patterns following annealing could actually not be used for determining the interstitial position.

\section{Substitutional and interstitial fractions}

Fig. 10 shows the fractions $f_{\mathrm{s}}$ and $f_{\mathrm{i}}$ of ${ }^{24} \mathrm{Na}$ on susbstitutional and interstitital lattice sites, as well as the $\operatorname{sum} f_{\text {sum }}=f_{\mathrm{s}}+f_{\mathrm{i}}$ of both, as a function of annealing temperature. The general picture is that in the as-implanted state interstitial sites dominate over substitutional ones, while following annealing at $800-900^{\circ} \mathrm{C}$, the interstitial fraction is greatly reduced in favour of the substitutional one, hence that site changes of $\mathrm{Na}$ took place. The $600^{\circ} \mathrm{C}$ annealing results for AlN show that this site change already partly happened at this lower annealing temperature. The scatter in the fractions derived for the GaN sample \#1 from pad and Timepix detector measurements is within the expected range of precision of our technique, where errors of $\pm 10 \%$ in sum fractions $f_{\text {sum }}$ are expected, due to the limited accuracy of background corrections for different measurement conditions [26]. We also performed 3-site fits where 


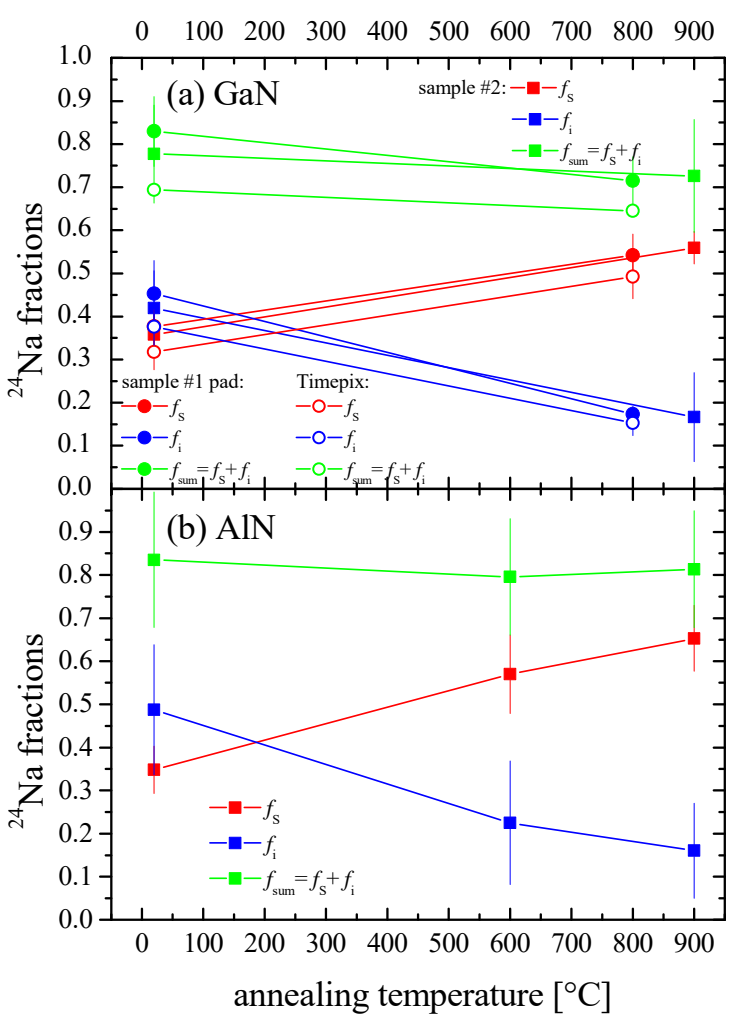

FIG 8. ${ }^{24} \mathrm{Na}$ in $\mathrm{GaN}$ (a) and $\mathrm{AlN}(\mathrm{b})$ : Fractions on substitutional $\mathrm{Ga}$ or $\mathrm{Al}\left(f_{\mathrm{s}}\right)$ and near octahedral interstitial $\mathrm{O}\left(f_{\mathrm{i}}\right)$ sites, as well as the sum of both $\left(f_{\text {sum }}\right)$. The error bars reflect the spread in fractions derived from the patterns of the four crystallographic directions measured at each temperature.

the first two sites were kept fixed at the substitutional $\mathrm{Ga}$ or $\mathrm{Al}$ site and the identified $\mathrm{Na}_{\mathrm{i}}$ positions near the $\mathrm{O}$ site, while the third site was varied over the whole range of sites calculated. However, this did not result in significant and consistent improvements in fit quality. One may hence conclude that additional lattice sites could not be identified, in particular no $\mathrm{Na}$ was found on substitutional $\mathrm{N}$ or interstitial $\mathrm{T}$ sites.

\section{DISCUSSION}

Our results fully confirm the co-existence of ${ }^{24} \mathrm{Na}$ near interstitial $\mathrm{O}$ and substitutional cation positions following RT implantation into GaN and AlN, as was sugested by Ronning et al. [16] on the basis of less detailed data. We also confirm the partial site change they reported for ${ }^{24} \mathrm{Na}$ in AlN following annealing at $800^{\circ} \mathrm{C}$. In addition, we were able to show the partial site change in $\mathrm{GaN}$ following $800-900^{\circ} \mathrm{C}$ annealing, which was not obvious in the experiments of Ronning et al.

Also in contrast to previous measurements [16], we were able to determine the positions of interstitial ${ }^{24} \mathrm{Na}$ parallel to the $c$-axis. In GaN sample \#1 we found within measurement 
accuracy the interstitial $\mathrm{Na}$ exactly at the $\mathrm{O}$ site, as predicted by theory [13]. However, in sample \#2 the derived ${ }^{24} \mathrm{Na}$ position was $-0.18 \AA$ off the $\mathrm{O}$ site, hence located closer to the HA site. While these different assessments could be due to limitations in the accuracy of our lattice location method, the fact that the displacements derived from all three off-surface directions of each sample are rather consistent, suggests that the ${ }^{24} \mathrm{Na}$ lattice sites might in fact differ by $\sim 0.2 \AA$ in between both samples (a more detailed discussion can be found in the supplementary material). The major known differences of the two samples are the implanted fluence $\left(2.9 \times 10^{13} \mathrm{~cm}^{-2}\right.$ for sample \#1 vs $4.8 \times 10^{12} \mathrm{~cm}^{-2}$ for sample \#2) and a smaller mosaic spread for sample \#1 [29], resulting from the use of a more advanced growth technique. Due to the extraordinary radiation hardness and dynamic annealing of GaN and AlN, no major effects of implantation damage are expected for the fluence range used in our experiments. For instance, for ${ }^{28} \mathrm{Si} \mathrm{RT}$ implantations in $\mathrm{GaN}$, no detectable damage could be observed with Rutherford Backscattering Spectrometry/Channeling (RBS/C) for fluences up to $10^{14} \mathrm{~cm}^{-2}$ $[19,35]$, the same applies to $10^{14} \mathrm{~cm}^{-2}{ }^{24} \mathrm{Mg}$ implantations investigated by X-ray diffraction [36]. In case of AlN, for $6 \times 10^{13} \mathrm{~cm}^{-2}{ }^{40} \mathrm{Ar}$ implantations performed at $15 \mathrm{~K}$ hardly any damage was visible by RBS/C [37]. Since the apparent slight shift of $\sim 0.2 \AA$ is close to the expected precision of our experiments [29], in order to proof this difference is real, more experiments with larger numbers of equivalent samples would be required, thus reducing statistical spreads.

In both GaN and AIN, annealing at elevated temperature induced site changes of interstitial $\mathrm{Na}$ to substitutional cation sites. We interpret these site changes as resulting from the onset of migration of interstitial $\mathrm{Na}_{i}^{+}$which then may combine with $\mathrm{Ga}$ or $\mathrm{Al}$ vacancies created during the implantation process. Similar behavior has been previously observed in emission channeling lattice location experiments following the implantation of the light alkali metal ${ }^{8} \mathrm{Li}$ in a large number of III-V and II-VI semiconductors including e.g. GaAs [38], GaP [38], InP [38], InSb [38], GaN [16, 39], and AlN [16]. In case of ${ }^{8} \mathrm{Li}$ in GaN and AlN the site changes from interstitial to substitutional cation sites took place at a temperature around $700 \mathrm{~K}$, corresponding to $\sim 427^{\circ} \mathrm{C}$. As we have previously reported, similar site change effects have also been observed following the implantation of ${ }^{27} \mathrm{Mg}$ in $\mathrm{GaN}[19,26,34]$ and AlN [28]. On the other hand, emission channeling studies with ${ }^{45} \mathrm{Ca}$ [40] and ${ }^{89} \mathrm{Sr}$ in $\mathrm{GaN}[16,40]$ identified only substitutional $\mathrm{Ga}$ sites while finding no indications of interstitial fractions for these heavier alkaline earths. One may therefore conclude that in GaN and AlN the coexistence of interstitial and substitutional sites, hence an amphoteric nature, seems to be a 
characteristic of the light alkali and alkaline earth metals, which all have been studied for use as $p$-type dopants in GaN [2, 12-15]. Establishing the amphoteric nature of these elements hence improves our understanding why $p$-type doping is not possible at all (e.g. using Be), or limited in its efficiency, as is the case for $\mathrm{Mg}$, the only technologically feasible $p$-type dopant of GaN.

By making some simple assumptions for the number of jumps $N$ which are needed for the interstitial ${ }^{24} \mathrm{Na}$ impurity until it combines with a vacancy, it is possible to derive estimates for the activation energy of interstitial migration $E_{\mathrm{M}}$ from the temperatures $T$ where the site changes occur and the duration of the annealing $\Delta t_{\mathrm{ann}}$. The mathematical formula appropriate for the case of ${ }^{24} \mathrm{Na}$ (simple Arrhenius model, implantation of long-lived radioisotope at room temperature, subsequent isochronous 10 min annealing steps) has been given in Ref. [21] as

$$
E_{\mathrm{M}}=k_{\mathrm{B}} T \ln \left[\frac{v_{0} \Delta t_{\mathrm{ann}}}{N \ln \left(f_{\mathrm{i} 0} / f_{\mathrm{i}}\right)}\right]
$$

where $v_{0}$ is the attempt frequency, $N$ the number of jumps, and $f_{i 0}$ and $f_{\mathrm{i}}$ the interstitial fractions before and after each annealing step. We have assumed $\nu_{0}=10^{12} \mathrm{~s}^{-1}$, and $N$ to range from $N=1$ (cation vacancy and interstitial $\mathrm{Na}_{\mathrm{i}}$ are next neighbours) to $\mathrm{N} \approx 200000$ (diffusion width corresponds to mean implantation depth). This results in estimated values of

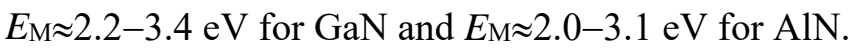

In Table II we have compiled the experimentally observed temperatures $T_{\mathrm{i} \rightarrow \mathrm{S}}$ of the site changes for $\mathrm{Li}, \mathrm{Na}$ and $\mathrm{Mg}$ in $\mathrm{GaN}$ and $\mathrm{AlN}$ and the corresponding estimates for the migration energies $E_{\mathrm{M}, \text { exp }}$ and compared them to theoretical predictions for $E_{\mathrm{M}}$ from the literature. In case of the alkaline earth $\mathrm{Be}$ in $\mathrm{GaN}$, preliminary results indicate the coexistence of substitutional and interstitial ${ }^{11} \mathrm{Be}$ at room temperature, with the major site change taking place around $350-400^{\circ} \mathrm{C}$ [42]. As a general rule, both in GaN and AlN, $T_{\mathrm{i} \rightarrow \mathrm{S}}$ is lowest for $\mathrm{Mg}$, followed by $\mathrm{Li}$ and highest for $\mathrm{Na}$, with all site changes in AlN occurring at lower temperatures than in $\mathrm{GaN}$. Since $\mathrm{Li}$ and $\mathrm{Na}$ are more volatile metals than $\mathrm{Mg}$, naively one might expect that $\mathrm{Li}$ and $\mathrm{Na}$ change sites at lower temperatures than $\mathrm{Mg}$. However, when comparing the ionic radii of $\mathrm{Li}^{+}, \mathrm{Na}^{+}$and $\mathrm{Mg}^{2+}$ one concludes that the temperatures of the site changes correlate with the ionic radii of the likely charge states of the interstitials, which are $1+$ for alkalis and 2+ for alkaline earths. Such a correlation was also predicted by theory [13]. A surprising fact is that the temperatures of the site changes are generally lower in AIN than in GaN. Since AlN has a greater bond strength and hence a more rigid lattice than GaN, which should hinder diffusion, this observation has no simple explanation. We also note that 
the interstitial diffusion of $\mathrm{Na}$ in $\mathrm{ZnO}$ is much faster than in $\mathrm{GaN}$, with $\mathrm{Na}$ site changes in $\mathrm{ZnO}$ happening already around $145^{\circ} \mathrm{C}$ (cf. Table II), although the two materials have quite similar structural properties.

TABLE II. . Comparison of the characteristics for the site changes of light alkalis and alkaline earths in $\mathrm{GaN}, \mathrm{AlN}$ and $\mathrm{ZnO} . T_{\mathrm{i} \rightarrow \mathrm{S}}$ is the temperature of the site changes from interstitial to substitutional $\mathrm{Ga}, \mathrm{Al}$ or $\mathrm{Zn}$ sites observed in emission channeling experiments following the implantation of the radioactive isotopes ${ }^{8} \mathrm{Li}\left(t_{1 / 2}=838 \mathrm{~ms}\right),{ }^{11} \mathrm{Be}\left(t_{1 / 2}=13.8 \mathrm{~s}\right)$, ${ }^{24} \mathrm{Na}\left(t_{1 / 2}=14.96 \mathrm{~h}\right)$ and ${ }^{27} \mathrm{Mg}\left(t_{1 / 2}=9.45 \mathrm{~min}\right)$. The characteristic time scales $\Delta t$ for the site changes are the radioactive lifetimes $\tau$ in case of the short-lived isotopes ${ }^{8} \mathrm{Li}(\tau=1.2 \mathrm{~s}),{ }^{11} \mathrm{Be}$ $(\tau=19.9 \mathrm{~s})$ and ${ }^{27} \mathrm{Mg}(\tau=13.6 \mathrm{~min})$, but a fixed annealing time of $10 \mathrm{~min}$ in the case of ${ }^{24} \mathrm{Na}$. $E_{\mathrm{M}, \exp }$ are the experimental estimates for the activation energies for migration of the interstitial impurities derived from $T_{\mathrm{i} \rightarrow \mathrm{s}}$, while $E_{\mathrm{M} \text {,theo }}$ are values predicted by theory, with $(\perp)$ indicating values for migration perpendicular and $(\|)$ parallel to the $c$-axis. The ionic radii given are the so-called "crystal ionic radii" for 4-fold coordination from Ref. [41].

\begin{tabular}{|l|l|l|l|l|l|}
\hline Material & Interstitial ion & $\begin{array}{l}\text { Ionic } \\
\text { radius }(\AA)\end{array}$ & $T_{\mathrm{i} \rightarrow \mathrm{S}}\left({ }^{\circ} \mathrm{C}\right)$ & $E_{\mathrm{M}, \exp }(\mathrm{eV})[\mathrm{Ref}]$ & $E_{\mathrm{M}, \text { theo }}(\mathrm{eV})[\mathrm{Ref}]$ \\
\hline \multirow{5}{*}{$\mathrm{GaN}$} & $\mathrm{Li}^{+}$ & 0.76 & $\sim 427$ & $\sim 1.7[16,39]$ & $\begin{array}{l}1.4(\perp) 1.55 \quad(\|) \quad[43], \\
1.16(\perp) 1.05(\|)[13]\end{array}$ \\
\cline { 2 - 7 } & $\mathrm{Be}^{2+}$ & 0.41 & $350-400$ & $1.2-2.1^{\mathrm{a}}[42]$ & $\begin{array}{l}1.2(\perp) 2.9 \quad(\|) \quad[14], \\
0.76(\perp) 1.88(\|)[13]\end{array}$ \\
\cline { 2 - 6 } & $\mathrm{Na}^{+}$ & 1.13 & $\sim 900$ & $2.2-3.4[$ this work] & $2.95(\perp) 2.41(\|)[13]$ \\
\cline { 2 - 6 } & $\mathrm{Mg}^{2+}$ & 0.71 & $\sim 400$ & $1.3-2.0[34]$ & $0.15(\perp) 0.68(\|)[44-45]$, \\
& & & & $2.20(\perp) 2.01(\|)[13]$ \\
\hline \multirow{3}{*}{$\mathrm{AlN}$} & $\mathrm{Li}^{+}$ & 0.76 & $\sim 427$ & $\sim 1.7[16]$ & \\
\cline { 2 - 6 } & $\mathrm{Na}^{+}$ & 1.13 & $600-900$ & $2.0-3.1[$ this work] & \\
\cline { 2 - 6 } & $\mathrm{Mg}^{2+}$ & 0.71 & $300-400$ & $1.1-1.7[28]$ & $0.74(\perp) 1.33(\|)[46]$ \\
\hline $\mathrm{ZnO}$ & $\mathrm{Na}^{+}$ & 1.13 & $\sim 145$ & $0.81-1.32[21]$ & \\
\hline
\end{tabular}

${ }^{\mathrm{a}}$ Based on a preliminary analysis of recent ${ }^{11} \mathrm{Be}$ lattice location measurements [45], the major site change of $\mathrm{Be}$ occurs around $350-400^{\circ} \mathrm{C}$, but there may be further contributions at higher and lower temperatures.

Comparing the experimental estimates $E_{\mathrm{M} \text {,exp }}$ to the theoretical predictions for $E_{\mathrm{M}}$, as shown in Table II, one concludes that there is usually good correspondence. An exception are the values of $0.15 \mathrm{eV}$ and $0.68 \mathrm{eV}$ predicted by Harafuji et al. [44-45] for migration of $\mathrm{Mg}$ in $\mathrm{GaN}$ perpendicular and parallel to the $c$-axis, which are by far too low to be compatible with the experimental estimate of $1.3-2.0 \mathrm{eV}$ of Ref. [33] and also do not scale well with all other theoretical predictions in Table II.

Macroscopic diffusion studies for light alkali and alkaline earth elements in GaN at temperatures around $900-1500^{\circ} \mathrm{C}$ give a somewhat disperse picture. While no data are available for $\mathrm{Li}$ and $\mathrm{Na}$, for $\mathrm{Be}$ in $\mathrm{GaN}$ an activation energy for macroscopic diffusion of 
$\sim 4 \mathrm{eV}$ was reported [47]. In the case of the major $p$-type dopant $\mathrm{Mg}$ in $\mathrm{GaN}$, several studies found no or very little diffusion [48-49], while others claim quite low activation energies, e.g. $1.3 \mathrm{eV}$ [50] and $1.9 \mathrm{eV}$ [51]. While low activation energies for $\mathrm{Mg}$ diffusion have often been associated with diffusion along dislocation lines [52-53], the emission channeling results suggest that in the absence of traps such as vacancies also simple interstitial diffusion should play a significant role. A carefully analyzed study led to the conclusion that macroscopic $\mathrm{Mg}$ diffusion in $\mathrm{GaN}$ occurs by the interstitial-substitutional mechanism with an activation energy of $5.0 \mathrm{eV}$ [54]. We note that an interstitial-substitutional diffusion mechanism is also what one would expect taking into account the emission channeling results showing the high interstitial diffusivities of $\mathrm{Li}, \mathrm{Be}, \mathrm{Na}$ and $\mathrm{Mg}$. The activation energy for macroscopic diffusion is in this case essentially the same as the activation energy for the dissociation of the substitutional impurity, $E_{\text {diss. }}$ Using positron annihilation spectroscopy, the creation of Ga vacancies in Be-doped $\mathrm{GaN}$ has recently been observed following prolonged ( $2 \mathrm{~h}$ ) annealing at $900^{\circ} \mathrm{C}$ [55]. The corresponding activation energy was derived as $E_{\text {diss }}=3.5 \mathrm{eV}$, which roughly coincides with the activation energy for macroscopic Be diffusion of $4.0 \mathrm{eV}$ reported in Ref. [47]. It has not been possible to directly determine $E_{\text {diss }}$ of substitutional $\mathrm{Li}, \mathrm{Be}, \mathrm{Na}$ and $\mathrm{Mg}$ in $\mathrm{GaN}$ and $\mathrm{AlN}$ using emission channeling, since our experimental setups are limited to $800-900^{\circ} \mathrm{C}$ annealing and thus can only reach the lower limit of the required temperature range. Note that we did not attempt to explore the Fermi level effect on substitutional vs interstitial Na preference predicted by theory [12], since implantations above $1 \times 10^{12} \mathrm{~cm}^{-2}$ already seem to push the $p$ - or $n$-doping type of $\mathrm{GaN}$ towards intrinsic conditions $[19,34]$.

\section{CONCLUSIONS}

Emission channeling studies of the lattice location of implanted ${ }^{24} \mathrm{Na}$ in $\mathrm{GaN}$ and $\mathrm{AlN}$ reveal the co-existence of interstitial $\mathrm{Na}$ near octahedral positions and substitutional $\mathrm{Na}$ on $\mathrm{Ga}$ or $\mathrm{Al}$ sites in the as-implanted state. Hence, $\mathrm{Na}$ is clearly confirmed as an amphoteric impurity in $\mathrm{GaN}$ and AlN. The interstitial position of $\mathrm{Na}$ could be determined close to the $\mathrm{O}$ site in $\mathrm{GaN}$, while somewhat shifted $(-0.126 \AA)$ towards the HA site in AlN. Annealing of the implanted GaN samples at $800-900^{\circ} \mathrm{C}$ and $\mathrm{AlN}$ at $600-900^{\circ} \mathrm{C}$ converted a significant fraction of the interstitial $\mathrm{Na}$ to the cation substitutional sites, a process which is explained by interstitial $\mathrm{Na}$ migration and combination with $\mathrm{Ga}$ or $\mathrm{Al}$ vacancies created during implantation. We estimate activation energies for $\mathrm{Na}$ migration as $2.2-3.4 \mathrm{eV}$ in $\mathrm{GaN}$ and $2.0-3.1 \mathrm{eV}$ in $\mathrm{AlN}$. The 
behaviour of implanted $\mathrm{Na}$ in GaN and $\mathrm{AlN}$ shows great similarity to the cases of $\mathrm{Li}$ and $\mathrm{Mg}$, for which similar lattice site changes from interstitial to substitutional have been reported previously. Since comparable phenomena were recently also observed for $\mathrm{Be}$ in $\mathrm{GaN}$ [42], this shows that all four light alkali metals and alkaline earths are amphoteric in GaN. The lattice site change temperatures and hence the activation energies for interstitial migration $E_{\mathrm{M}}$ were found to be correlated with the ionic radii of $\mathrm{Li}^{+}, \mathrm{Be}^{2+}, \mathrm{Na}^{+}$, and $\mathrm{Mg}^{2+}$ and are in agreement with most theoretical predictions. Moreover, our emission channeling results support that long-range diffusion of these elements should occur by the interstitialsubstitutional mechanism.

\section{SUPPLEMENTARY MATERIAL}

See supplementary material for additional sample characteristics, background correction, many-beam simulations, theoretical patterns from different lattice sites in GaN and AlN, Timepix measurements of $\mathrm{GaN} \# 1$, pad detector measurements of $\mathrm{GaN} \# 2$, and a number of other comments.

\section{ACKNOWLEDGMENTS}

We thank M. Kappers from the University of Cambridge for growing GaN sample \#1, and O. Briot from the University of Montpellier for growing the AlN sample. We acknowledge the beam time provided by the ISOLDE collaboration. This work was funded by the Portuguese Foundation for Science and Technology (FCT) through project CERN-FIS-PAR-0005-2017 and the strategic project UID/Multi/04349/2019, by the FWO Vlaanderen and the KU Leuven Research Fund (SF/18/008). The ISOLDE beam times were supported by the European Commission through the Horizon 2020 program (grant number 654002 ENSAR2).

\section{DATA AVAILABILITY}

The data that support the findings of this study are available from the corresponding author upon reasonable request.

\section{REFERENCES}

[1] J. I. Pankove and J. A. Hutchby, "Photoluminescence of ion-implanted GaN," J. Appl. Phys. 47, 5387 (1976).

[2] M. A. Reshchikov and H. Morkoç, "Luminescence properties of defects in GaN," J. Appl. Phys. 97, 061301 (2005). 
[3] Y. Mori, "Recent progress of Na-flux method for GaN crystal growth", Jpn. J. Appl. Phys. 58, SC0803 (2019).

[4] A. Denis, G. Goglio, and G, Demazeau "Gallium nitride bulk crystal growth processes: A review," Mater. Sci. Eng. Reports 50, 167 (2006).

[5] J. A. Freitas Jr., "Properties of the state of the art of bulk III-V nitride substrates and homoepitaxial layers,” J. Phys. D: Appl. Phys. 43, 073001 (2010).

[6] T. Paskova, D. A. Hanser, and K. R. Evans, "GaN substrates for III-nitride devices," Proceedings of the IEEE 98, 1324 (2010).

[7] D. Ehrentraut and E. Meissner, "A brief review on the Na-flux method toward growth of large-size GaN crystal," in Technology of Gallium Nitride Crystal Growth, edited by D. Ehrentraut, E. Meissner, and M. Bockowski (Springer, 2010) p 235.

[8] M. Imade, M. Maruyama, M. Yoshimura, and Y. Mori, "Growth of bulk GaN crystals by the Na-flux point seed technique,” Jpn. J. Appl. Phys. 53, 05FA06 (2014).

[9] H. Yamane, M. Shimada, S. J. Clarke, and F. J. Disalvo, "Preparation of GaN single crystals using a Na flux," Chemistry of Materials 9, 413 (1997).

[10] F. Kawamura, H. Umeda, M. Morishita, M. Kawahara, M. Yoshimura, Y. Mori, T. Sasaski, and Y. Kitaoka "Growth of a two-inch GaN single crystal substrate using the Na flux method,” Jpn. J. Appl. Phys. 45, L1136 (2006).

[11] P. Von Dollen, S. Pimputkar, M. A. Alreesh, H. Albrithen, S. Suihkonen, S. Nakamura, and J. S. Speck, "A new system for sodium flux growth of bulk GaN. Part I: System development,” J. Cryst. Growth 456, 58 (2016).

[12] J. Neugebauer and C. Van de Walle, "Chemical trends for acceptor impurities in GaN," J. Appl. Phys. 85, 3003 (1999).

[13] G. Miceli and A. Pasquarello, "Migration of $\mathrm{Mg}$ and other interstitial metal dopants in GaN,” Phys. Status Solidi RRL 111700081 (2017).

[14] C. G. Van de Walle, S. Limpijumnong, and J. Neugebauer, "First-principles studies of beryllium doping of GaN,” Phys. Rev. B 63, 245205 (2001).

[15] C. G. Van de Walle and J. Neugebauer, "First-principles calculations for defects and impurities: Applications to III-nitrides,” J. Appl. Phys. 95, 3851 (2004).

[16] C. Ronning, M. Dalmer, M. Uhrmacher, M. Restle, U. Vetter, L. Ziegeler, H. Hofsäss, T. Gehrke, K. Jarrendahl, R. F. Davis, and ISOLDE collaboration, "Ion implanted dopants in GaN and AlN: Lattice sites, annealing behavior, and defect recovery," J. Appl. Phys. 87, 2149 (2000). 
[17] H. Hofsäss and G. Lindner, "Emission channeling and blocking," Physics Reports 201, 121 (1991).

[18] U. Wahl, "Advances in electron emission channeling measurements in semiconductors," Hyperf. Inter. 129, 349 (2000).

[19] L. M. C. Pereira, A. Vantomme, and U. Wahl, "Characterizing defects with ion beam analysis and channeling techniques," in Characterisation and Control of Defects in Semiconductors, edited by F. Tuomisto (The Institution of Engineering and Technology, Stevenage, UK, 2019), pp. 501-563.

[20] R. Catherall, W. Andreazza, M. Breitenfeldt, A. Dorsival, G. J. Focker, T. P. Gharsa, T. J. Giles, J. L. Grenard, F. Locci, P. Martins, S. Marzari, J. Schipper, A. Shornikov, and T. Stora, “The ISOLDE facility,” J. Phys. G: Nucl. Part. Phys. 44, 094002 (2017).

[21] U. Wahl, J. G. Correia, L. Amorim, S. Decoster, M. R. da Silva, and L. M. C. Pereira, “Lattice sites of Na dopants in ZnO,", Semicond. Sci. Technol. 31, 095005 (2016).

[22] M. R. Silva, U. Wahl, J. G. Correia, L. M. Amorim, and L. M. C. Pereira, "A versatile apparatus for on-line emission channeling experiments," Rev. Sci. Instrum. 84, 073506 (2013).

[23] U. Wahl, J. G. Correia, A. Czermak, S. G. Jahn, P. Jalocha, J. G. Marques, A. Rudge, F. Schopper, J. C. Soares, A. Vantomme, and P. Weilhammer, "Position-sensitive Si pad detectors for electron emission channeling experiments," Nucl. Instrum. Meth. Phys. Res. A 524, 245 (2004).

[24] X. Llopart, R. Ballabriga, M. Campbell, L. Tlustos, and W. Wong, "Timepix, a 65k programmable pixel readout chip for arrival time, energy and/or photon counting measurements,” Nucl. Instrum. Meth. Phys. Res. A 581485 (2007).

[25] M. Campbell, "10 years of the Medipix2 collaboration," Nucl. Instrum. Meth. Phys. Res. A $633 \mathrm{~S} 1$ (2011).

[26] E. David-Bosne, U. Wahl, J. G. Correia, T. A. L. Lima, A. Vantomme, and L. M. C. Pereira, "A generalized fitting tool for analysis of two-dimensional channeling patterns," Nucl. Instrum. Meth. Phys. Res. B 462, 102 (2020).

[27] U. Wahl, A. Vantomme, G. Langouche, J. P. Araújo, L. Peralta, J. G. Correia, and the ISOLDE collaboration, "Emission channeling studies of Pr in GaN," J. Appl. Phys. 88, 1319 (2000).

[28] L. M. Amorim, U. Wahl, L. M. C. Pereira, S. Decoster, D. J. Silva, M. R. da Silva, A. Gottberg, J. G. Correia, K. Temst, and A. Vantomme, "Precise lattice location of substitutional and interstitial Mg in AlN,” Appl. Phys. Lett. 103262102 (2013). 
[29] More details are included in the supplementary material.

[30] S. Ruffenach-Clur, O. Briot, J. L. Rouvière, B. Gil, and R. L. Aulombard, "MOVPE growth and characterization of $\mathrm{Al}_{x} \mathrm{Ga}_{1-x} \mathrm{~N}$," Mater. Sci. Engin. B 50219 (1997).

[31] V. Srikant, J. S. Speck, and D. R. Clarke, "Mosaic structure in epitaxial thin films having large lattice mismatch,” J. Appl. Phys. 824286 (1997).

[32] B. De Vries, U. Wahl, S. Ruffenach, O. Briot, and A. Vantomme, "Influence of crystal mosaicity on axial channeling effects and lattice site determination of impurities," Appl. Phys. Lett. 103172108 (2013).

[33] B. De Vries, "Lattice site location of impurities in group III nitrides using emission channeling," PhD thesis, KU Leuven, 2006, CERN-THESIS-2005-102 https://cds.cern.ch/record/1640588

[34] U. Wahl, L. M. Amorim, V. Augustyns, A. Costa, E. David-Bosne, T. A. L. Lima, G. Lippertz, J. G. Correia, M. R. da Silva, M. J. Kappers, K. Temst, A. Vantomme, and L. M. C. Pereira, "Lattice location of Mg in GaN: A fresh look at doping limitations," Phys. Rev. Lett. 118095501 (2017).

[35] S. O. Kucheyev, J. S. Williams, C. Jagadish, J. Zou., G. Li, and A. I. Titov, "Effect of ion species on the accumulation of ion-beam damage in GaN," Phys. Rev. B 64035202 (2001).

[36] J. S. Chan, N. W. Cheung, L. Schloss, E. Jones, W. S. Wong, N. Newman, X. Liu, E. R. Weber, A. Gassman, and M. D. Rubin, "Thermal annealing characteristics of Si and Mgimplanted GaN thin films,” Appl. Phys. Lett. 682702 (1996).

[37] E. Wendler and W. Wesch, "Ar implantation of InSb and AlN at $15 \mathrm{~K}$," Nucl. Instrum. Meth. Phys. Res. B 242562 (2006).

[38] U. Wahl and the ISOLDE collaboration, "Emission channeling studies of $\mathrm{Li}$ in semiconductors," Physics Reports 280, 145 (1997).

[39] M. Dalmer, M. Restle, M. Sebastian, U. Vetter, H. Hofsäss, M. D. Bremser, C. Ronning, R. F. Davis, U. Wahl, K. Bharuth-Ram, and the ISOLDE collaboration, "Lattice site location studies of ion implanted ${ }^{8} \mathrm{Li}$ in GaN," J. Appl. Phys. 843085 (1998).

[40] B. De Vries, A. Vantomme, U. Wahl, J. G. Correia, J. P. Araújo, W. Lojkowski, D. Kolesnikov, and the ISOLDE collaboration, "Lattice site location and annealing behavior of implanted Ca and Sr in GaN,” J. Appl. Phys. 100023531 (2006).

[41] R. D. Shannon, "Revised effective ionic radii and systematic studies of interatomic distances in halides and chalcogenides", Acta Crystallogr. A 32, 751 (1976). 
http://isolde.web.cern.ch/updates/isolde-newsletter-2019, and to be published.

[43] F. Bernardini F and V. Fiorentini, "Incorporation, diffusion, and electrical activity of Li in GaN,” Phys. Rev. B 6112598 (2000).

[44] K. Harafuji, T. Tsuchiya, and K. Kawamura, "Magnesium diffusion in wurtzite-type GaN crystal," Phys. Stat. Sol. (c) 02240 (2003).

[45] K. Harafuji, T. Tsuchiya, and K. Kawamura "Molecular dynamics of magnesium diffusion in wurtzite-type GaN crystal,” Jpn. J. Appl. Phys. A 43522 (2004).

[46] G. Y. Huang, C. Y. Wang, and J. T. Wang, "First-principles study of diffusion of Li, Na, $\mathrm{K}$ and Ag in ZnO," J. Phys.: Condens. Matter 21345802 (2009).

[47] O. Koskelo, U. Köster, F. Tuomisto, K. Helariutta, M. Sopanen, S. Suihkonen, O. Svensk, and J. Räisänen, "Migration kinetics of ion-implanted beryllium in $\mathrm{ZnO}$ and GaN," Phys. Scr. 88035603 (2013).

[48] R. G. Wilson, J. M. Zavada, X. A. Cao, R. K. Singh, S. J. Pearton, H. J. Guo, S. J. Pennycook, M. Fu, J. A. Sekhar, V. Scarvepalli, R. J. Shu, J. Han, D. J. Rieger, J. C. Zolper, and C. R. Abernathy, "Redistribution and activation of implanted S, Se, Te, Be, Mg, and C in GaN,” J. Vac. Sci. Technol. A 171226 (1999).

[49] Y. L. Chang, M. Ludowise, D. Lefforge, and B. Perez, "Study of Mg diffusion during metalorganic chemical vapor deposition of GaN and AlGaN," Appl. Phys. Lett. 74688 (1999).

[50] C. J. Pan and G. C. Chi, "The doping of GaN with Mg diffusion," Solid State Electronics 43621 (1999).

[51] Z. Benzarti, I. Halidou, Z. Bougrioua, T. Boufaden, and B. El Jani, "Magnesium diffusion profile in GaN grown by MOVPE," J. Cryst. Growth 3103274 (2008).

[52] S. Porowski, I. Grzegory, D. Kolesnikov, W. Lojkowski, V. Jager, W. Jager, V. Bogdanov, T. Suski, and S. Krukowski, "Annealing of GaN under high pressure of nitrogen," J. Phys.: Condens. Matter 1411097 (2002).

[53] K. Harafuji and M. Kawamura, "Magnesium diffusion at dislocation in wurtzite-type GaN crystal,” Jpn. J. Appl. Phys. A 446495 (2005).

[54] K. Köhler, R. Gutt, J. Wiegert, and L. Kirste, "Diffusion of Mg dopant in metal-organic vapor-phase epitaxy grown $\mathrm{GaN}$ and $\mathrm{Al}_{x} \mathrm{Ga} 1_{-x \mathrm{~N}}$,” J. Appl. Phys. 113073514 (2013).

[55] F. Tuomisto, V. Prozheeva, I. Makkonen, T. H. Myers, M. Bockowski, and H. Teisseyre, "Amphoteric Be in GaN: Experimental evidence for switching between substitutional and interstitial lattice sites", Phys. Rev. Lett. 119, 196404 (2017). 
GaN RT experiment simulation $42 \% \mathrm{Na}_{i}+36 \% \mathrm{~S}_{\mathrm{Ga}}$ sites
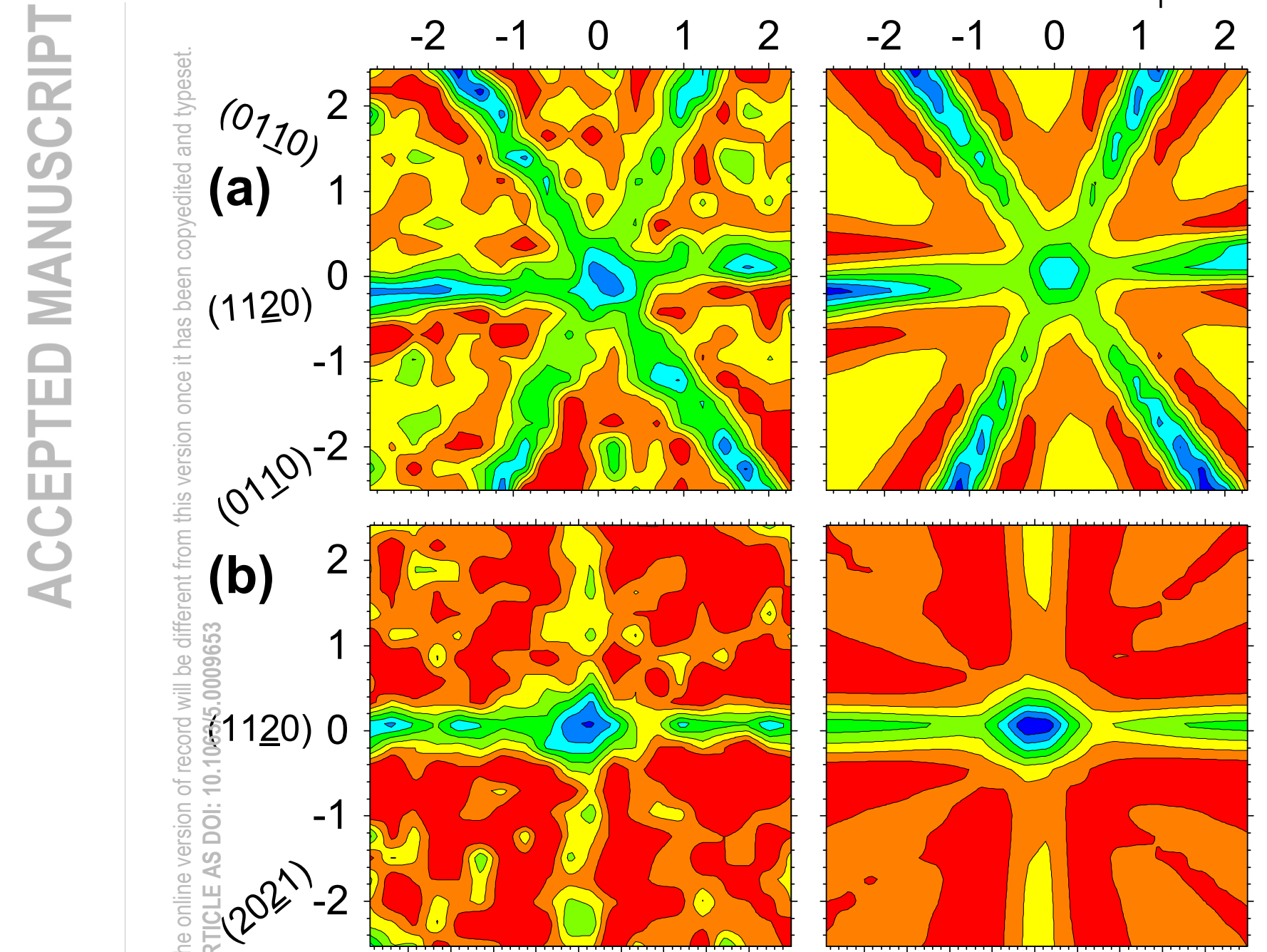

(e) [0001]
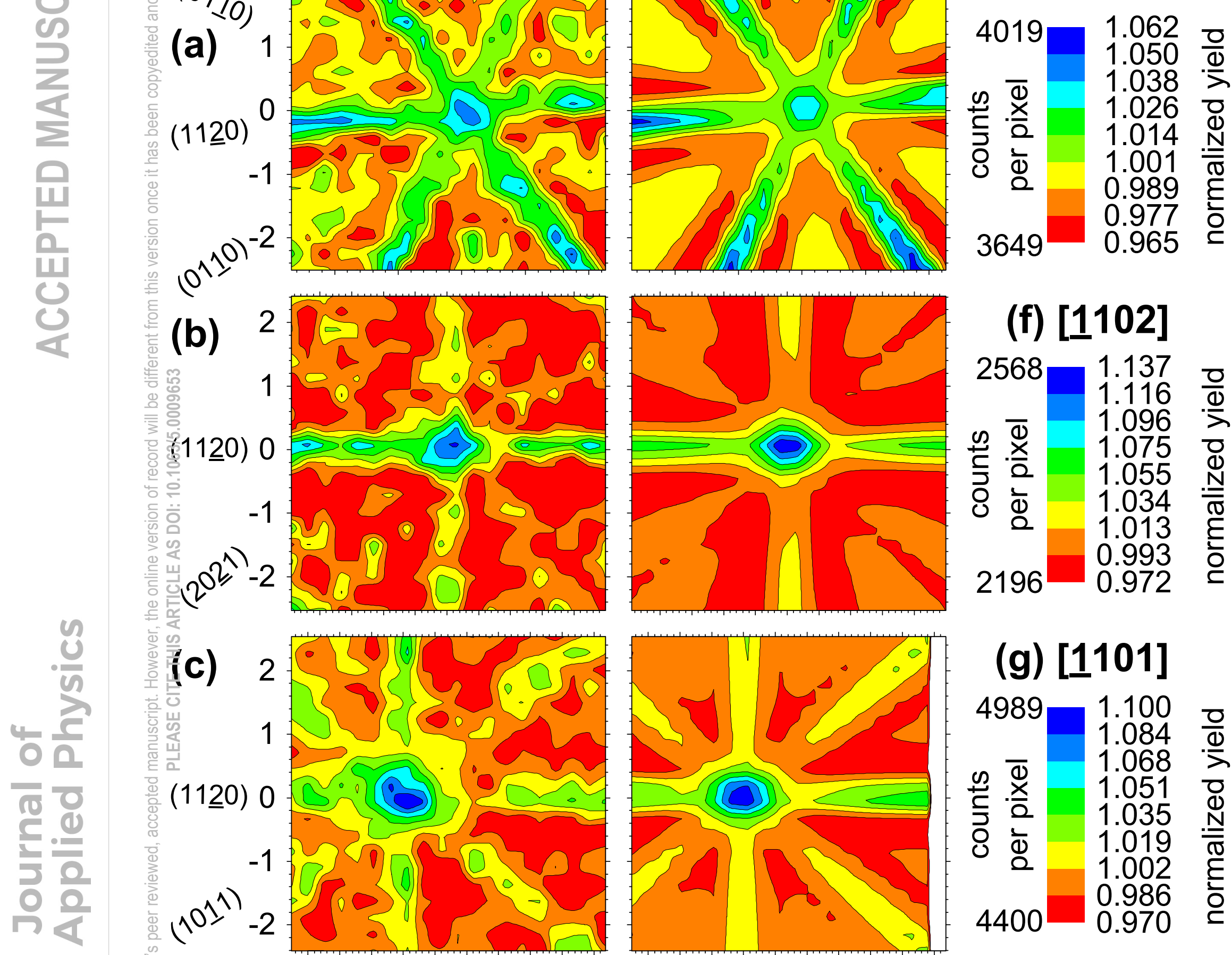

(f) [1102]
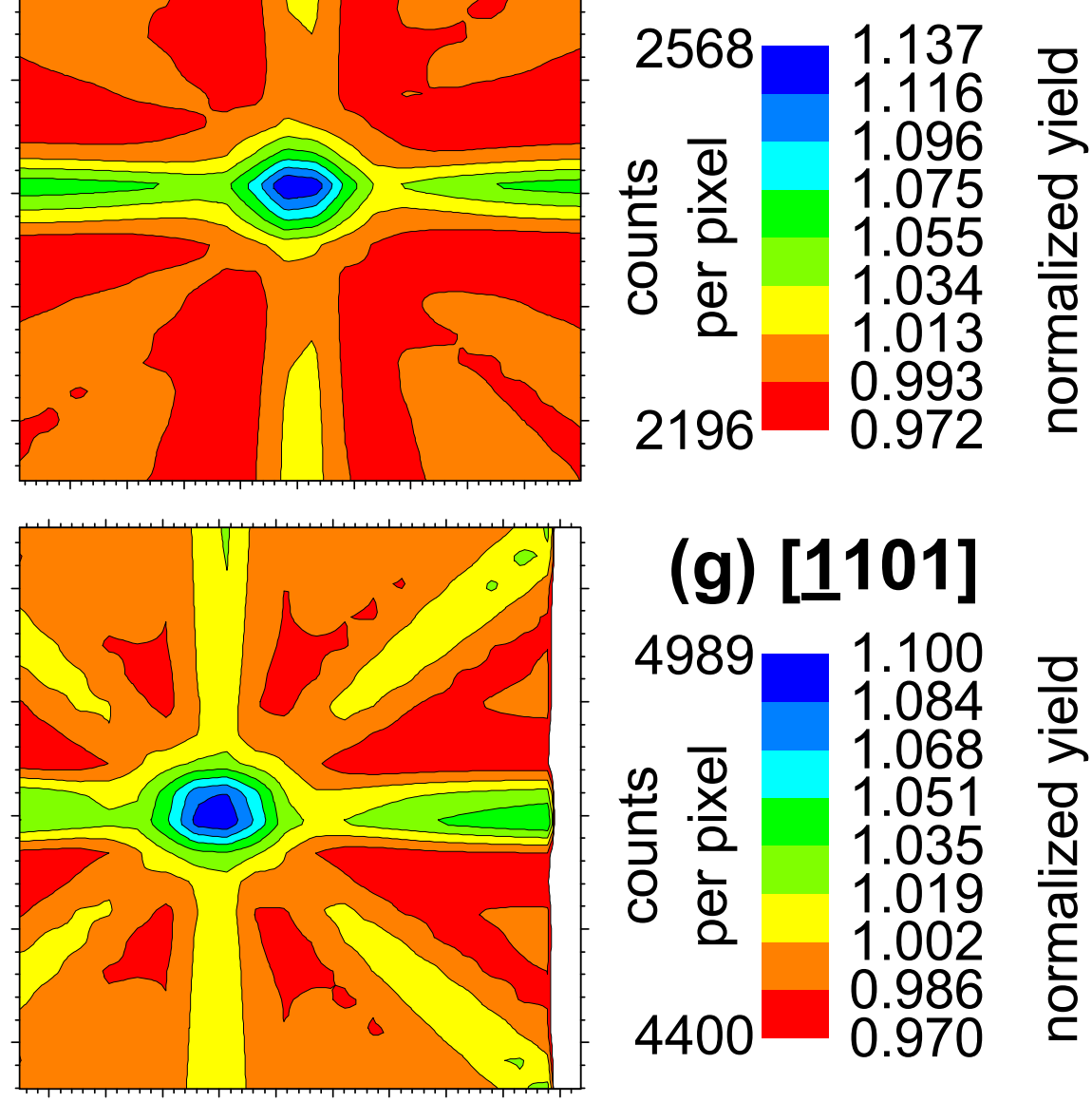

(g) [1101]

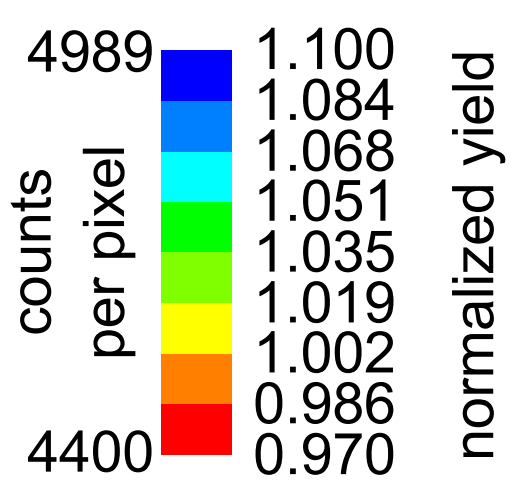

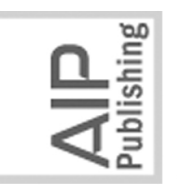
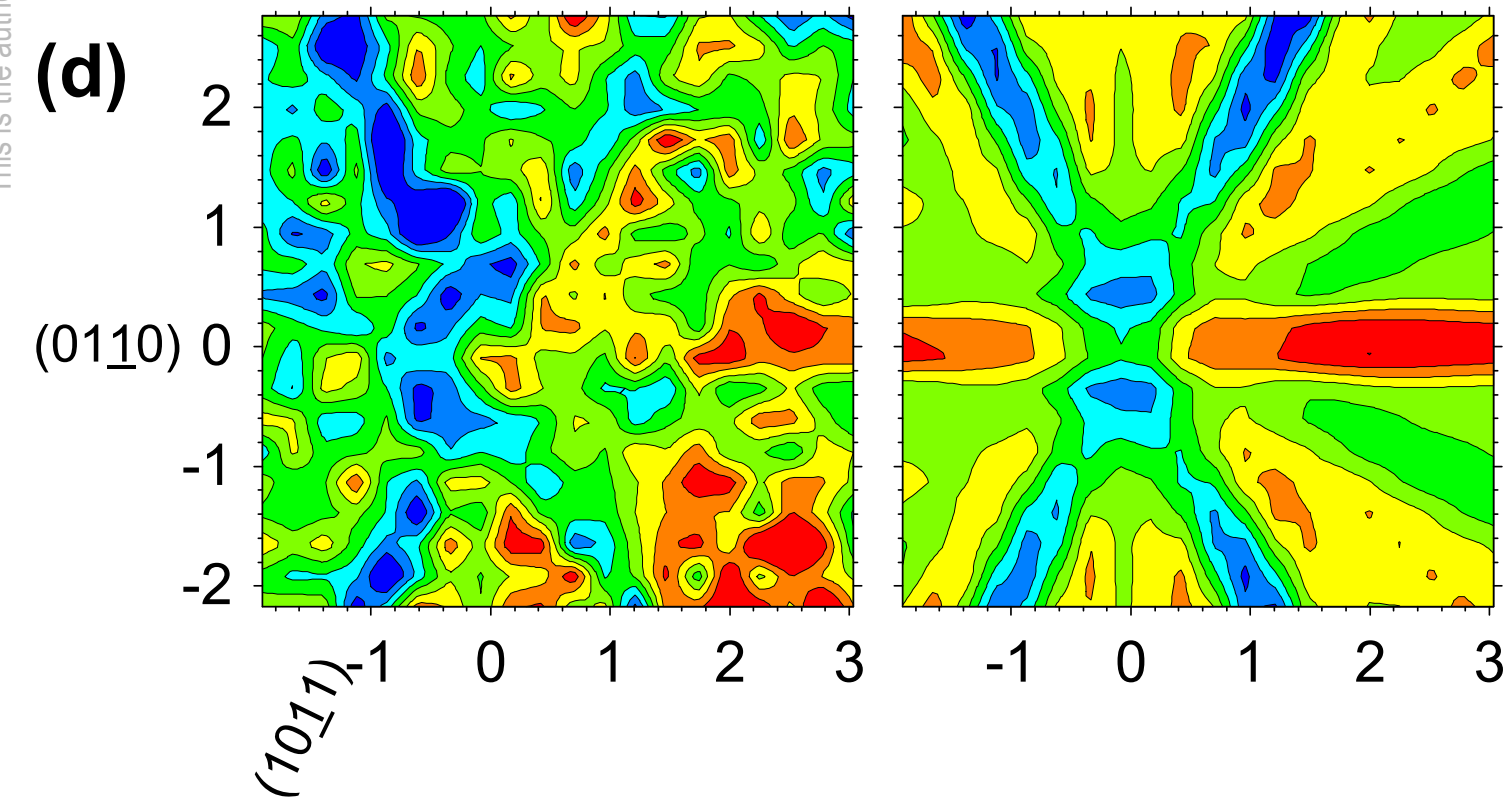

(h) [2113]

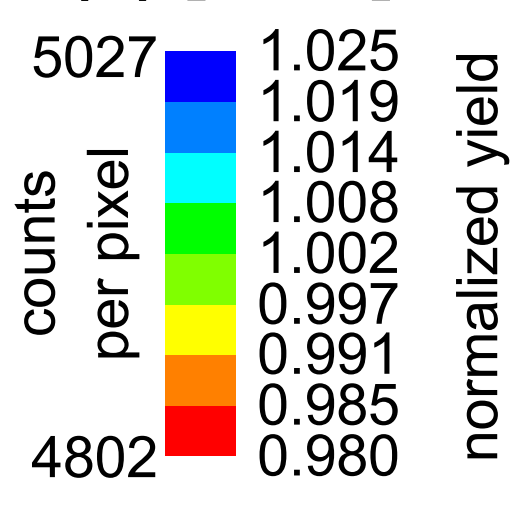


GaN $T_{A}=900^{\circ} \mathbf{C}$ experiment simulation $17 \% \mathrm{Na}_{i}+56 \% \mathrm{~S}_{\mathrm{Ga}}$ sites
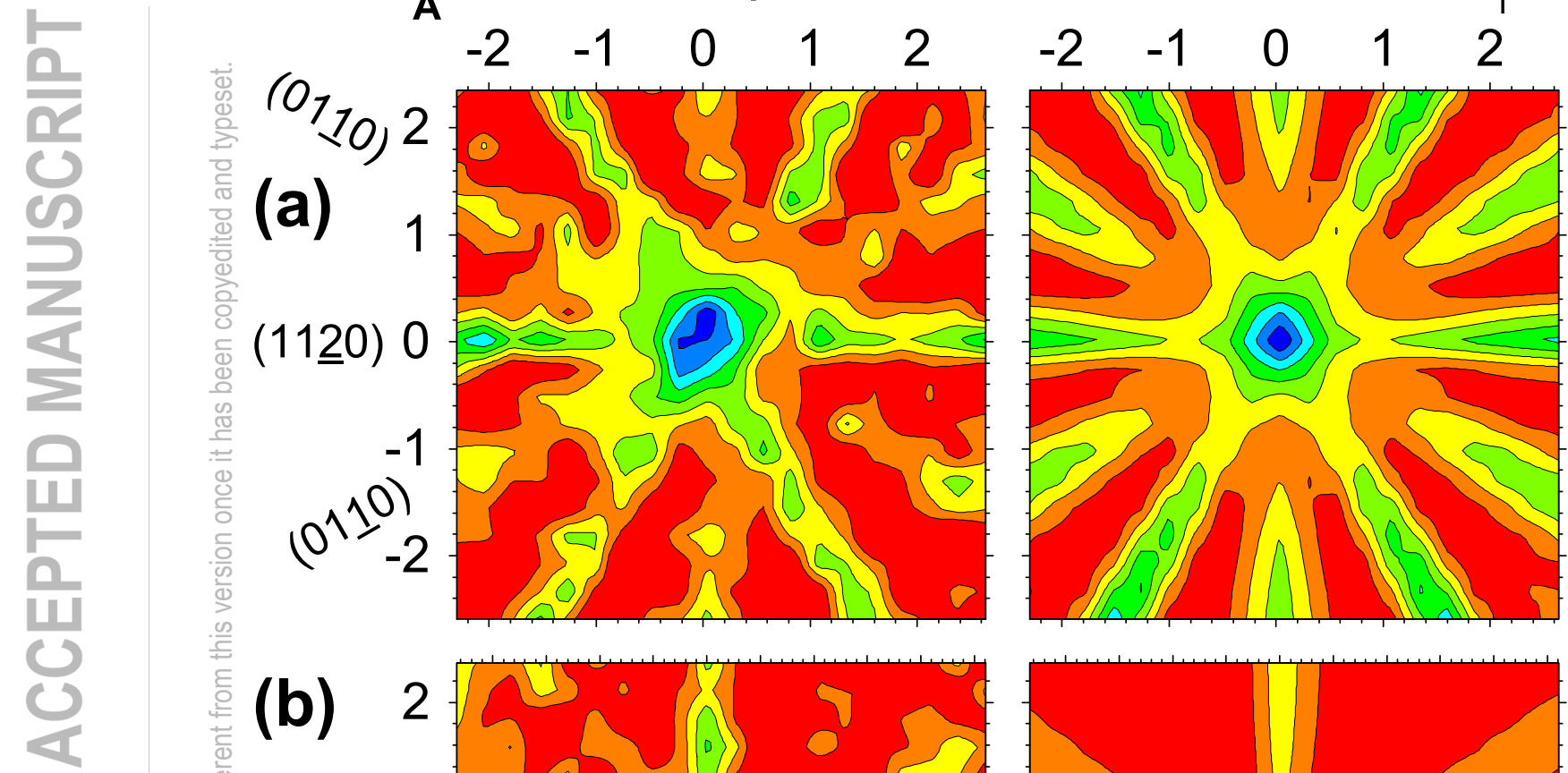

(e) [0001]
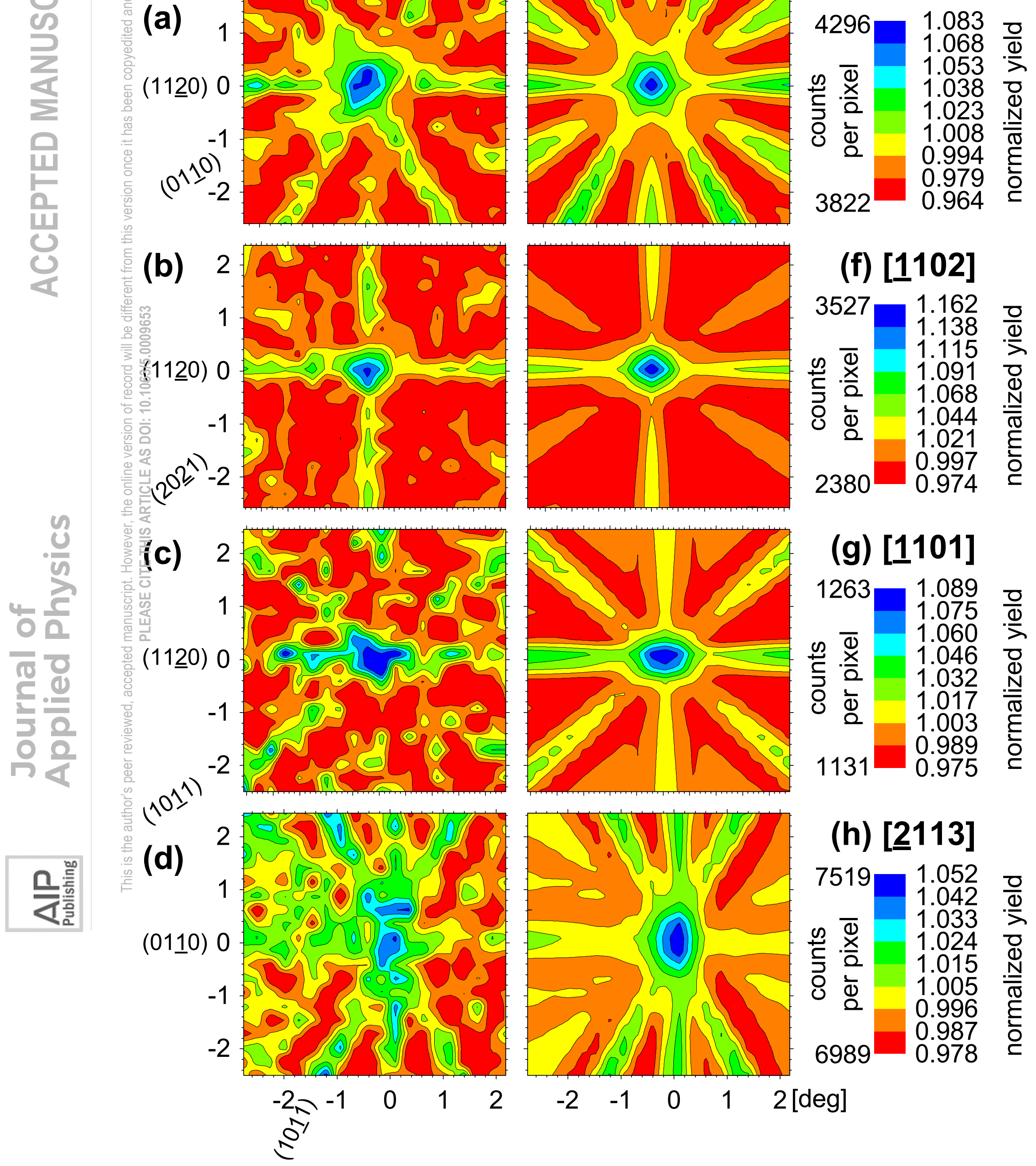

(g) [1101]
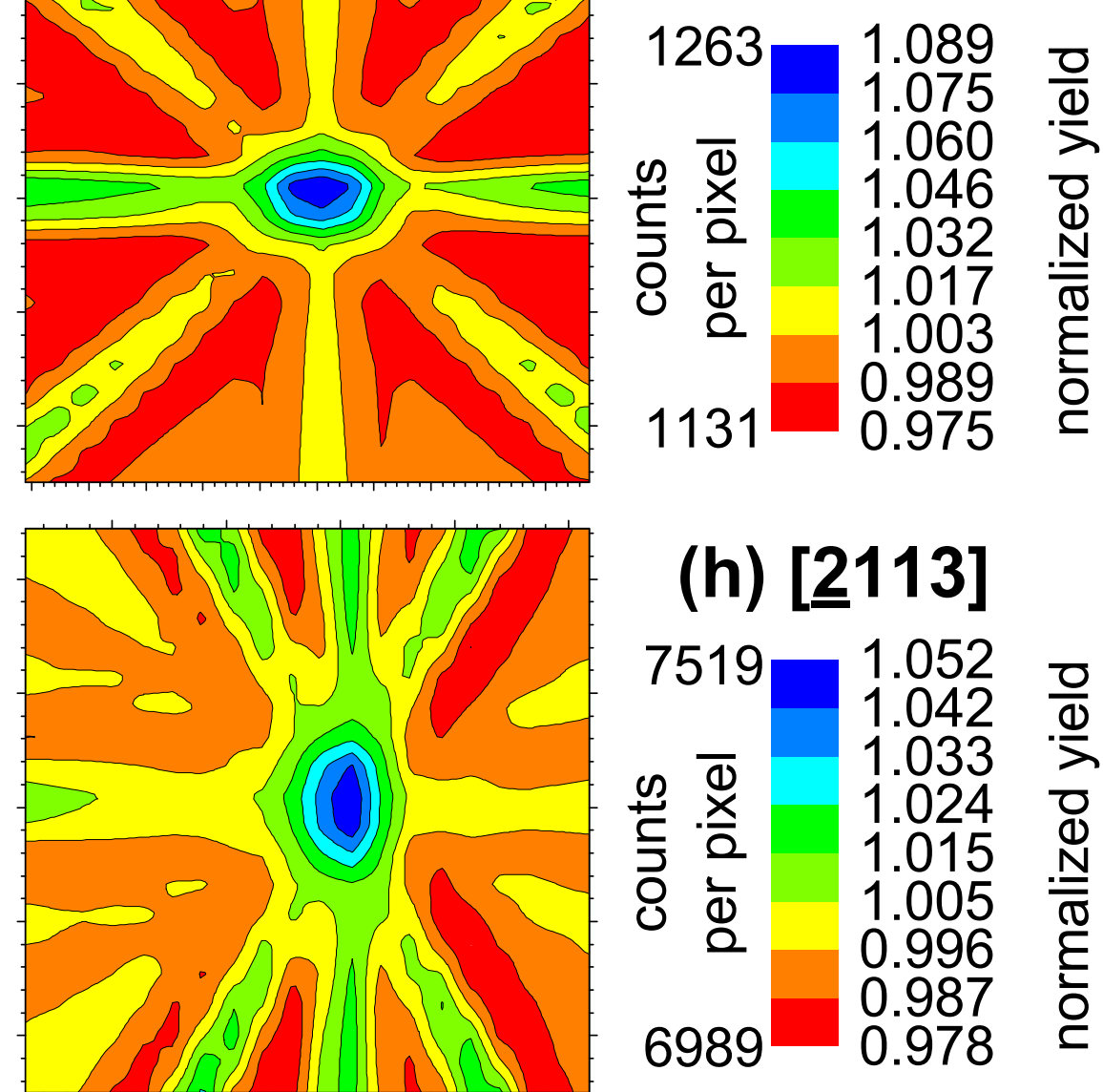

\section{(h) [2113]}

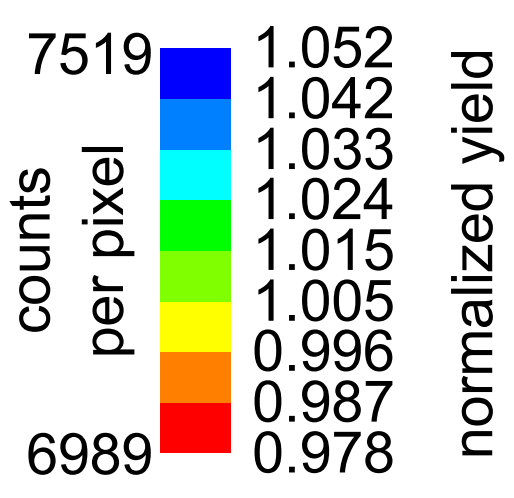

$\begin{array}{lllll}-2 & -1 & 0 & 1 & 2 \text { [deg] }\end{array}$ 
AIN RT experiment simulation $49 \% \mathrm{Na}_{\mathrm{i}}+35 \% \mathrm{~S}_{\mathrm{Al}}$ sites
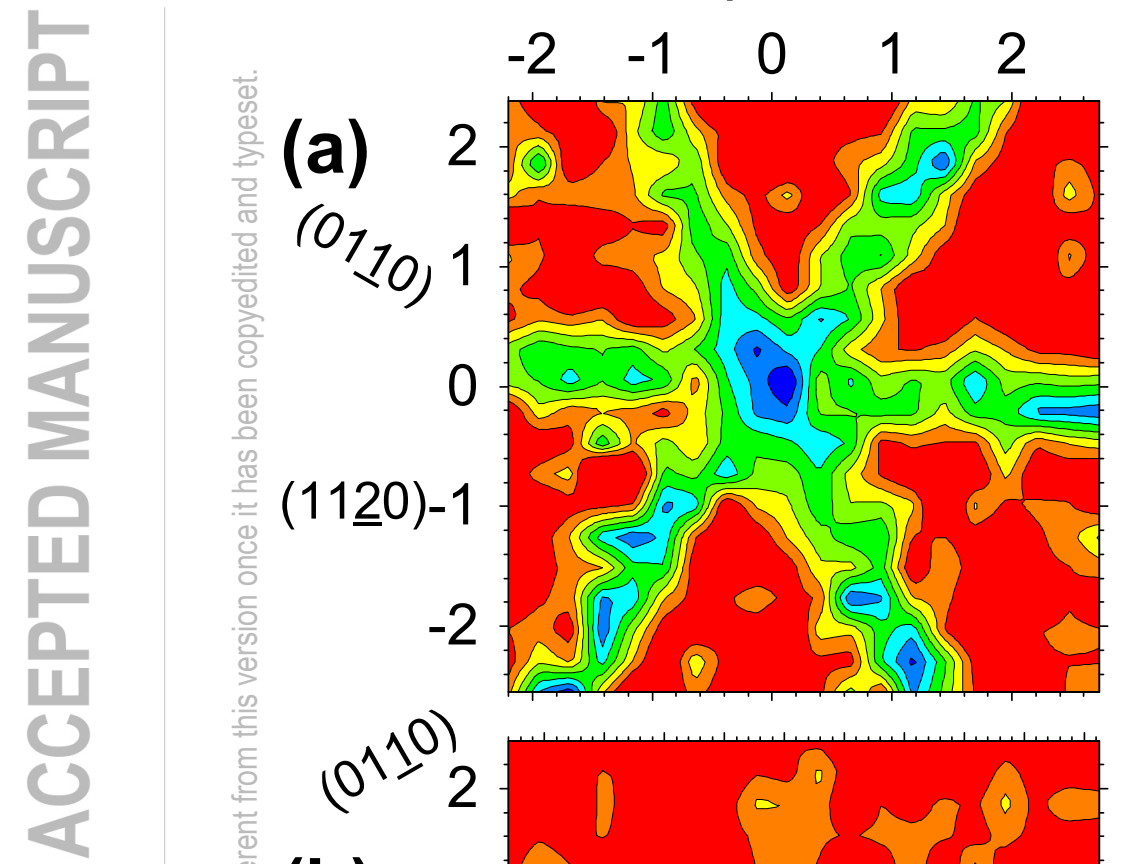

$\begin{array}{lllll}-2 & -1 & 0 & 1 & 2\end{array}$
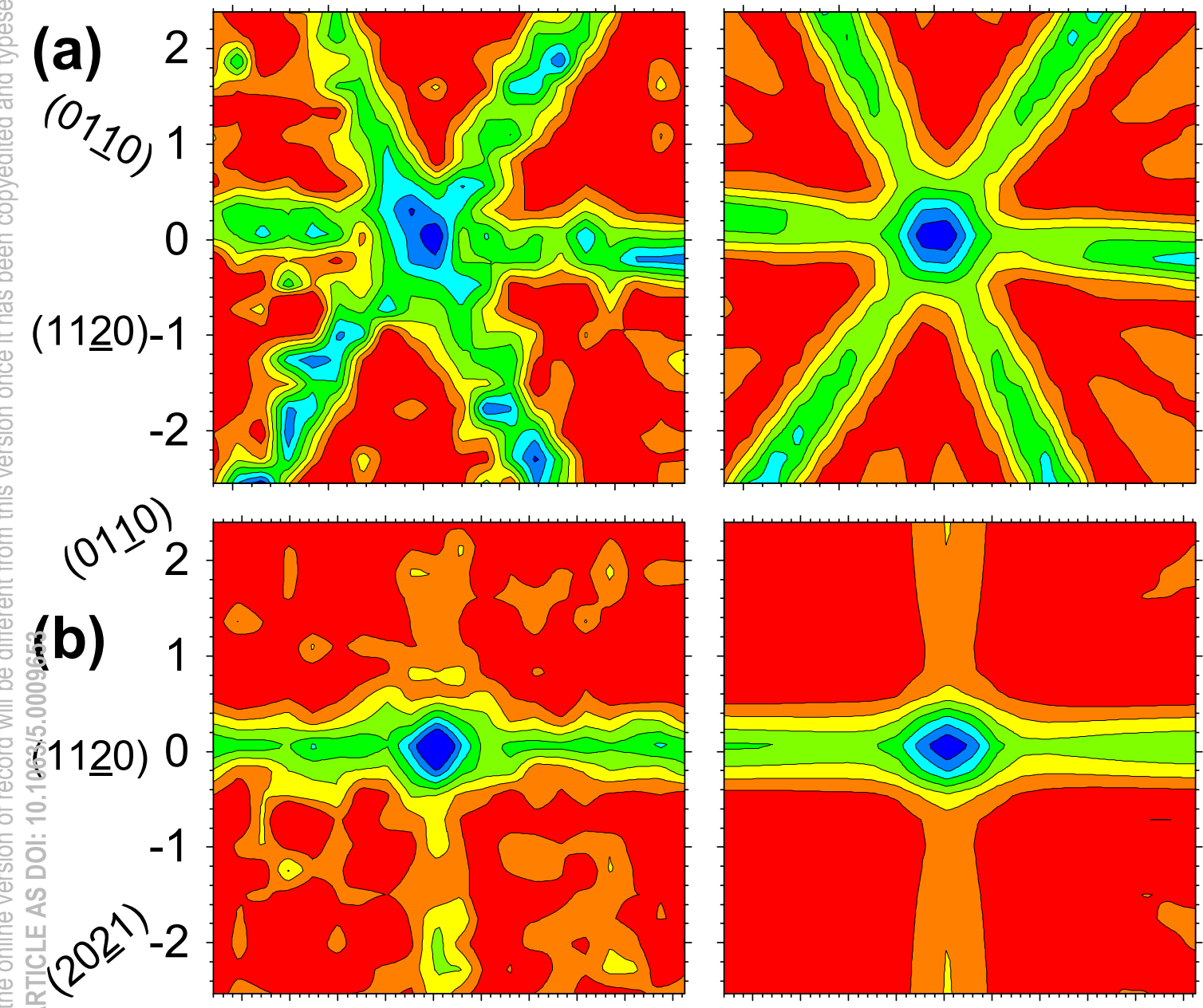

(e) [0001]

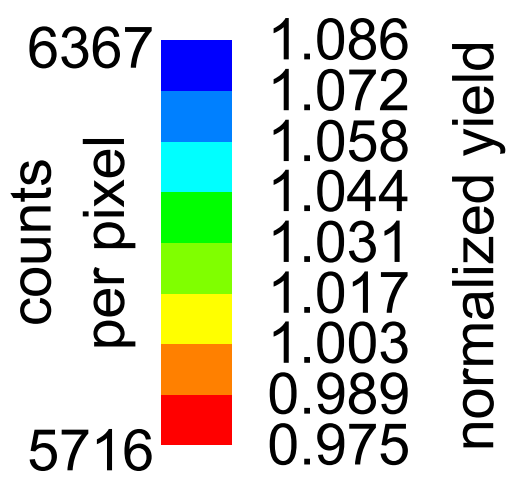

(f) [1102]
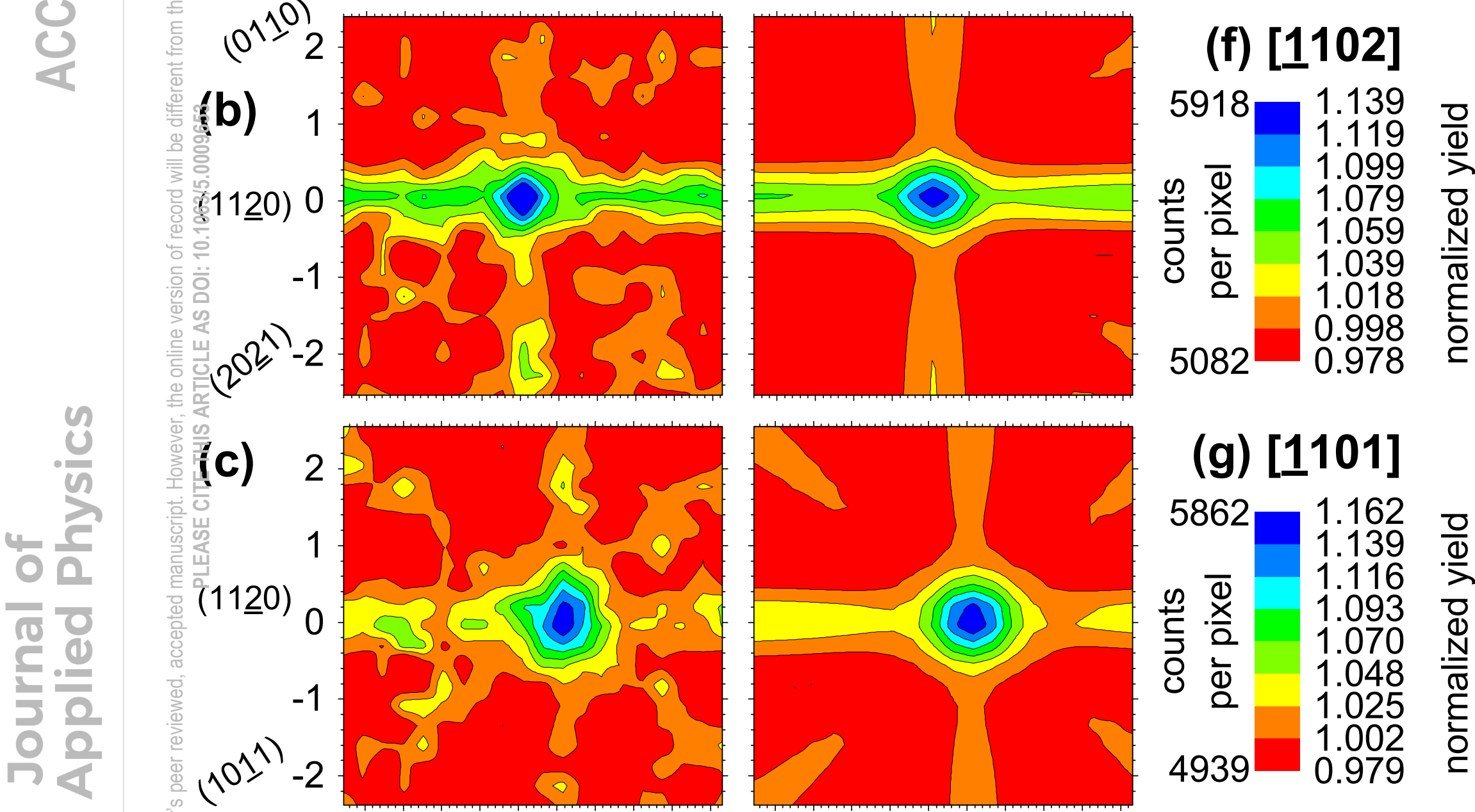

(g) [1101]
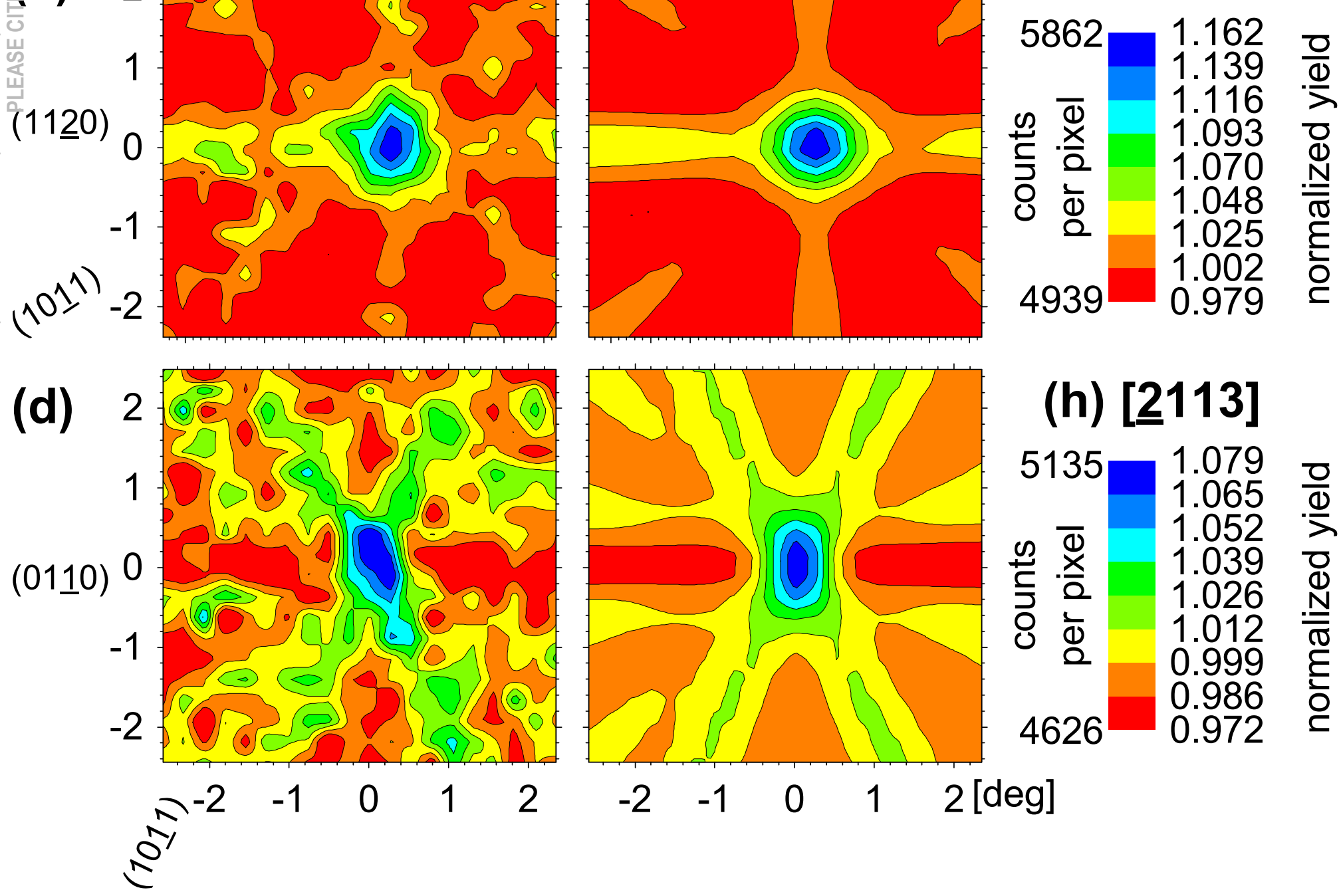

(h) [2113]

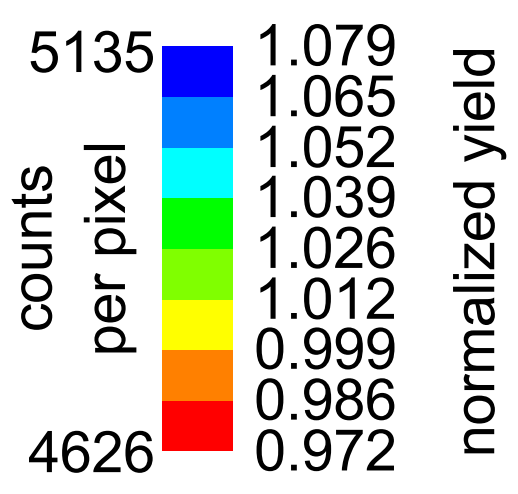

$\begin{array}{lllll}-2 & -1 & 0 & 1 & 2 \text { [deg] }\end{array}$ 
AIN $T_{A}=900^{\circ} \mathrm{C}$ experiment simulation $16 \% \mathrm{Na}_{\mathrm{i}}+65 \% \mathrm{~S}_{\mathrm{Al}}$ sites
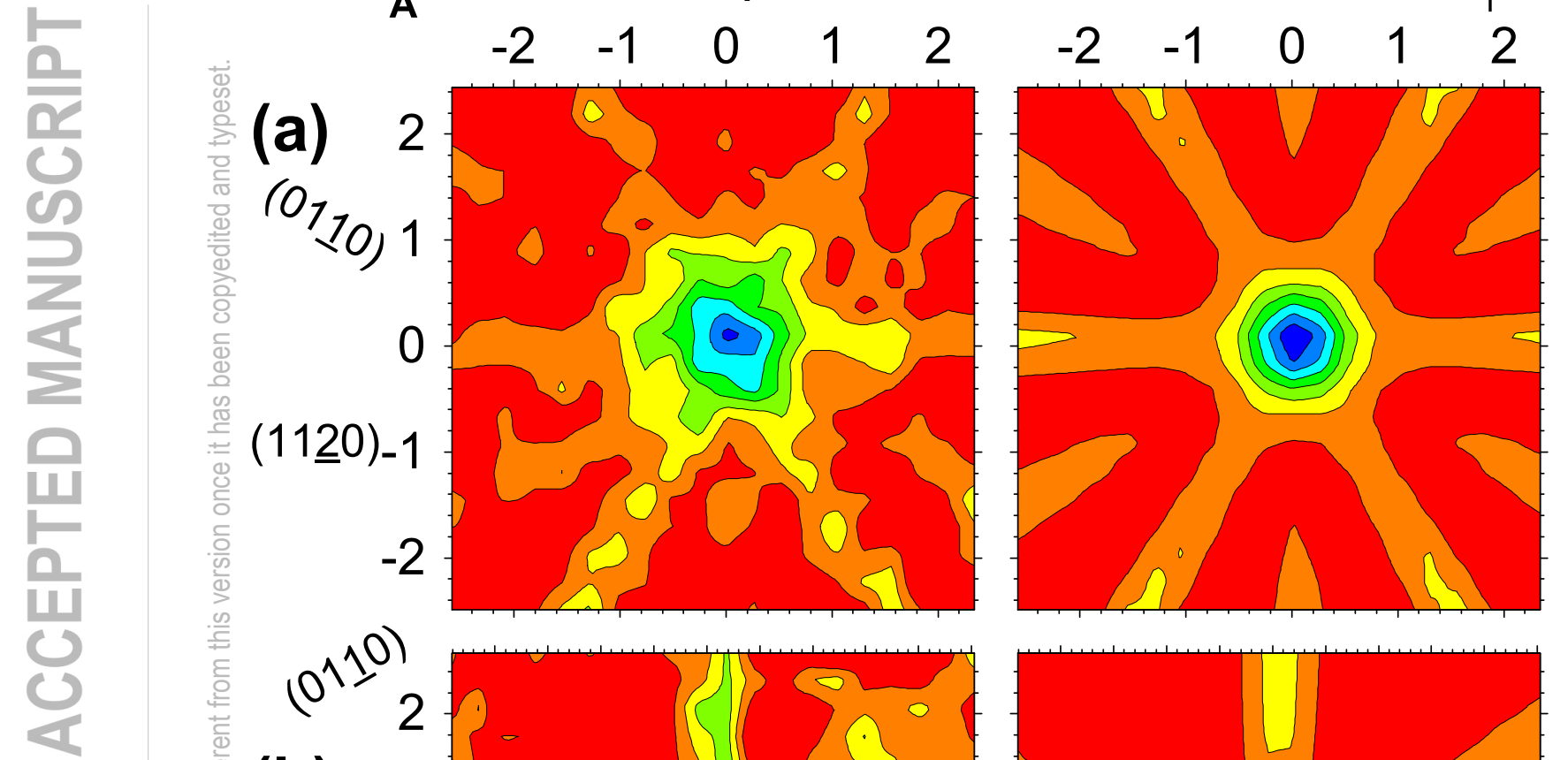

(e) [0001]
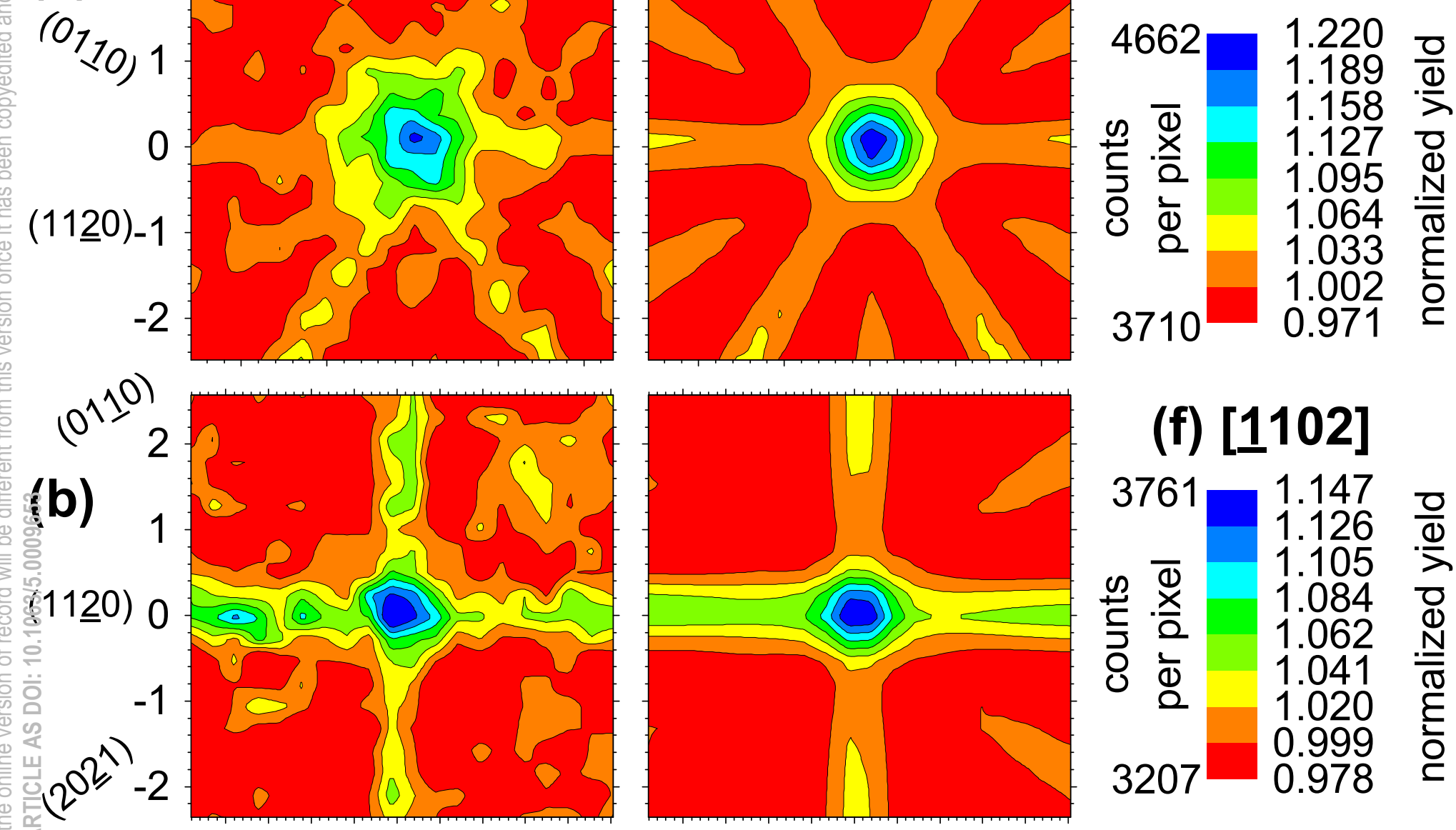

(f) [1102]
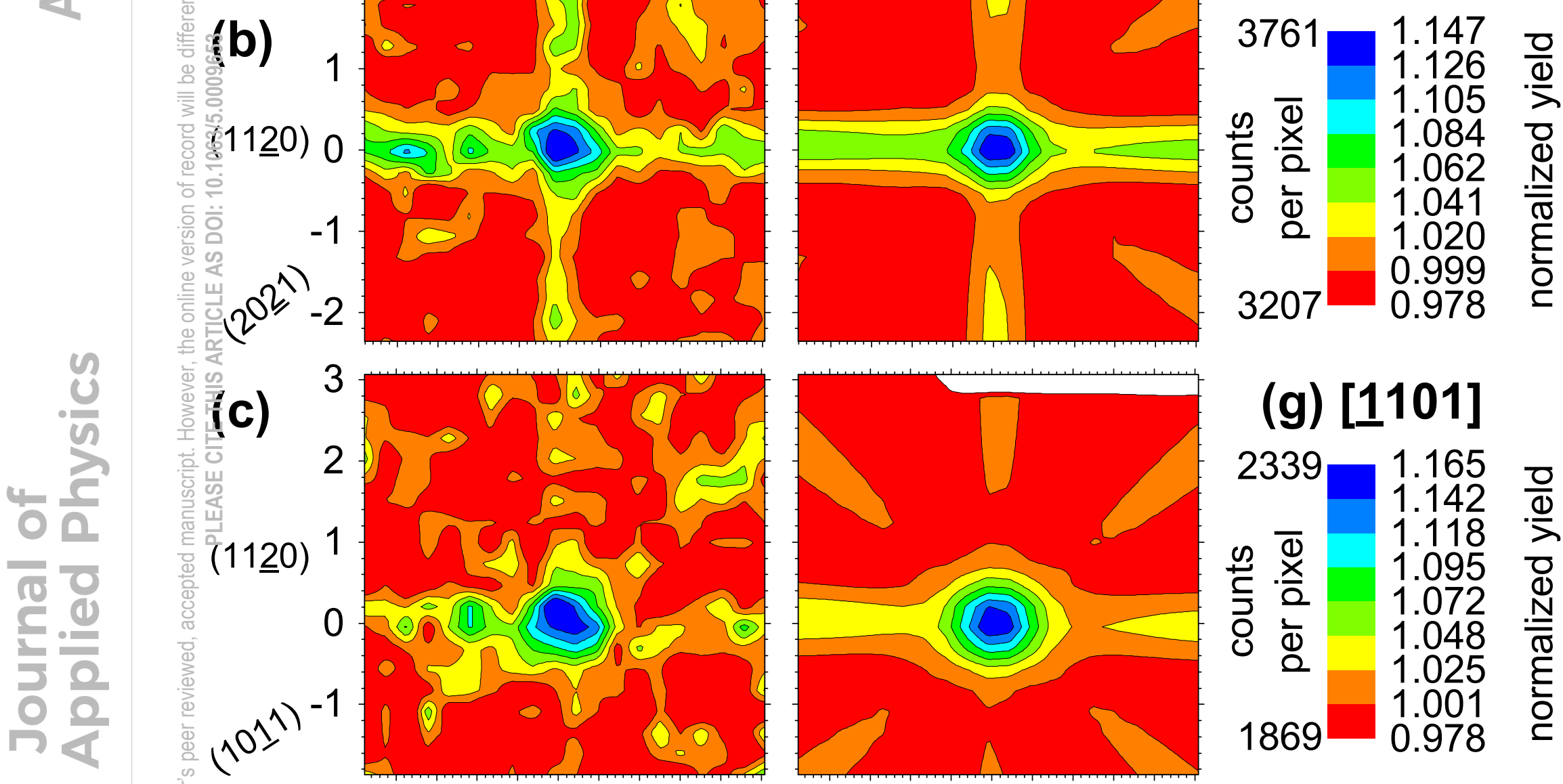

\section{(g) [1101]}

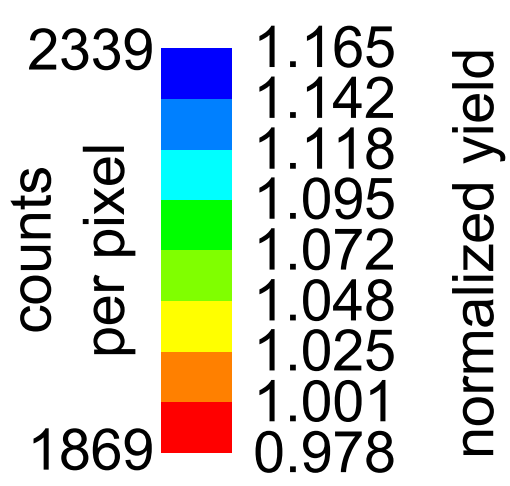
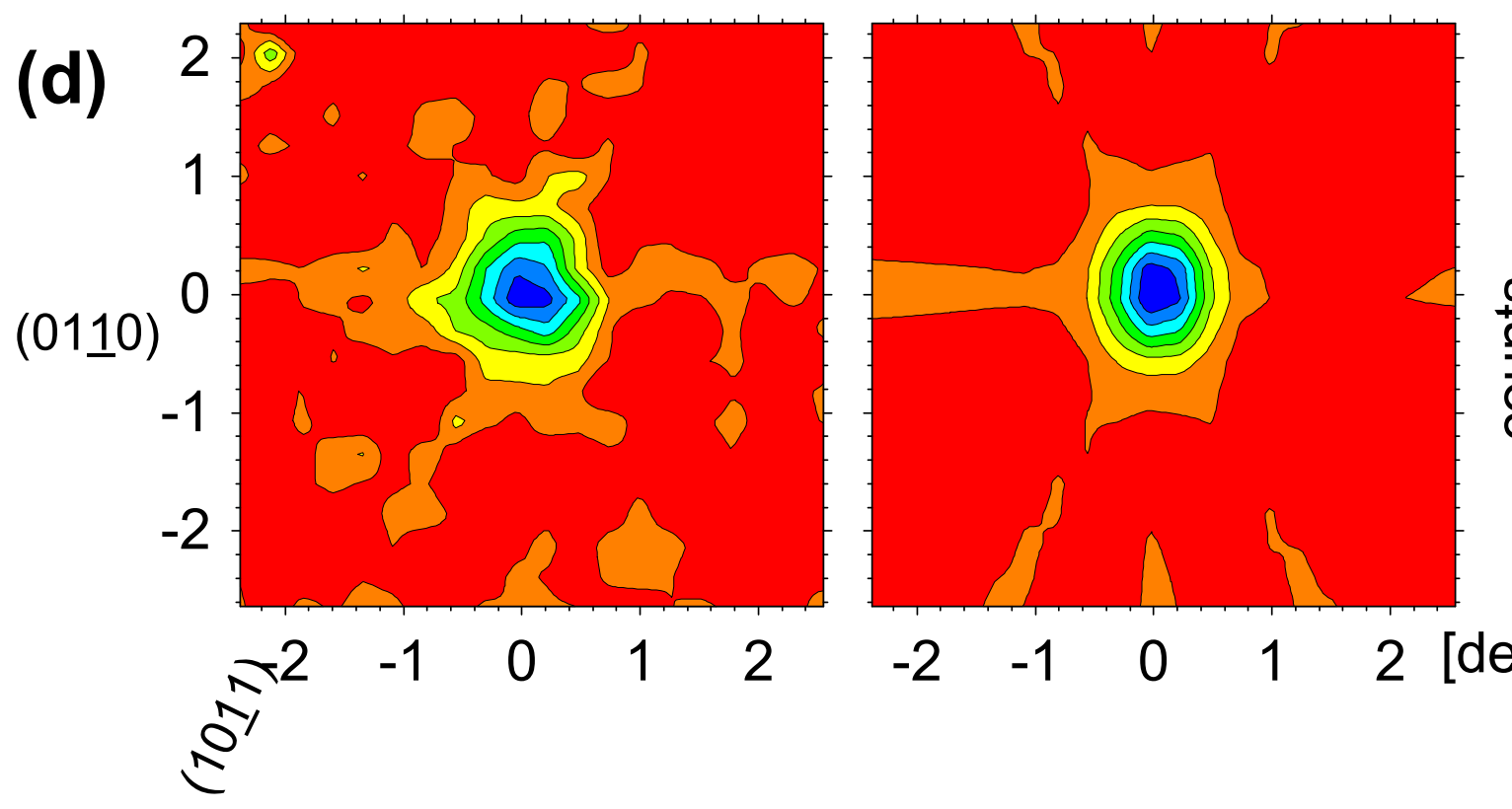

(h) [2113]

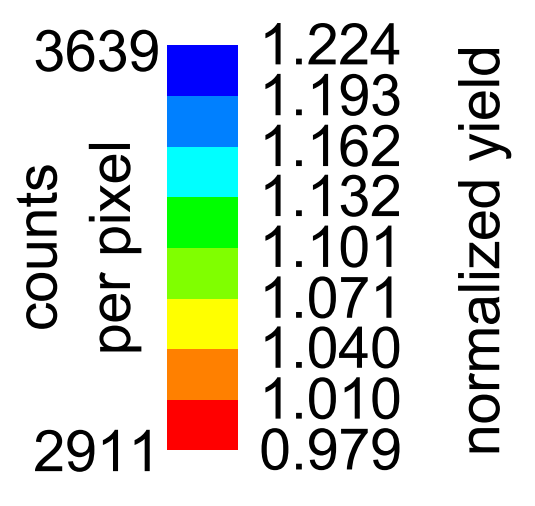

$\begin{array}{lllll}-2 & -1 & 0 & 1 & 2\end{array}$ [deg] 


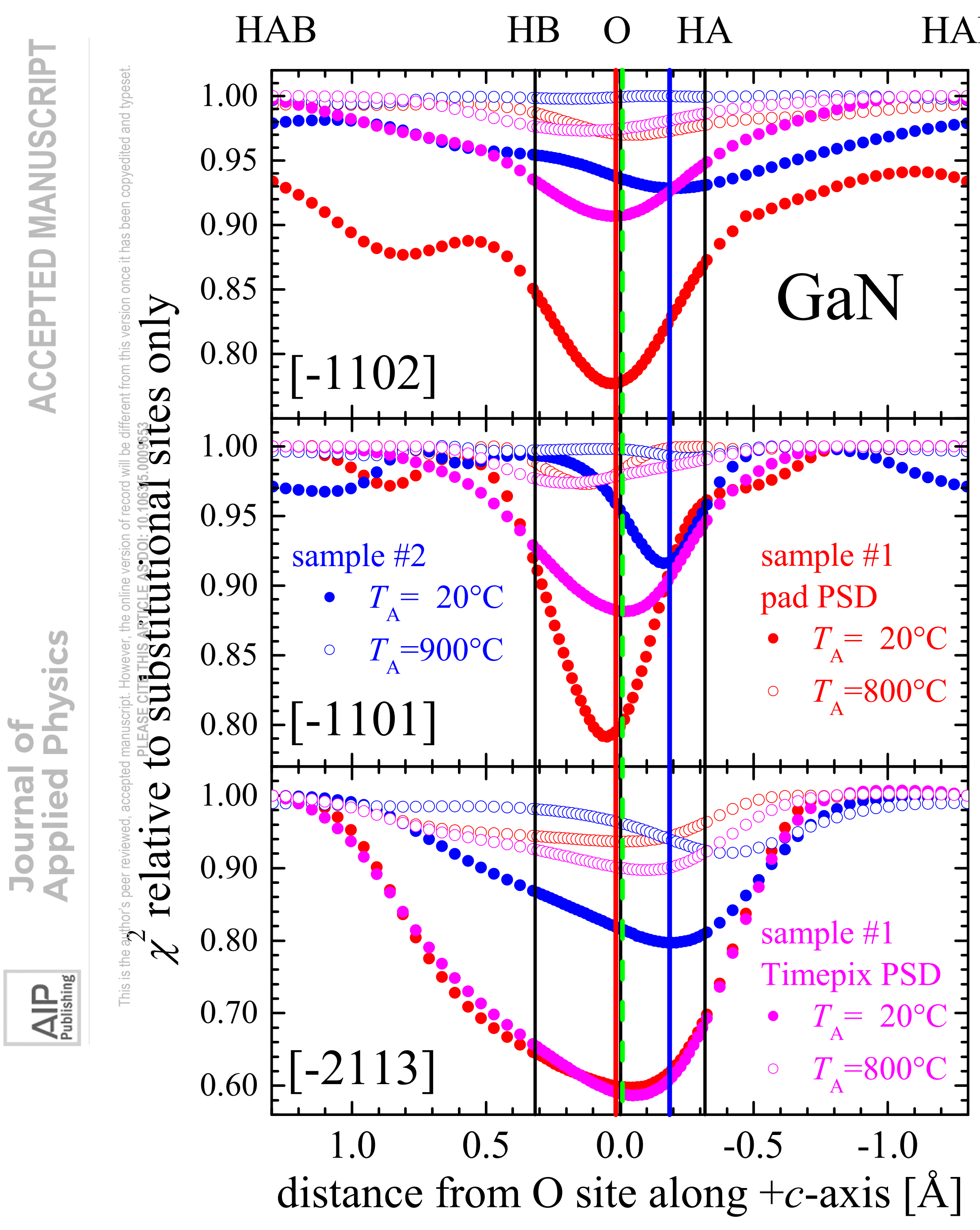




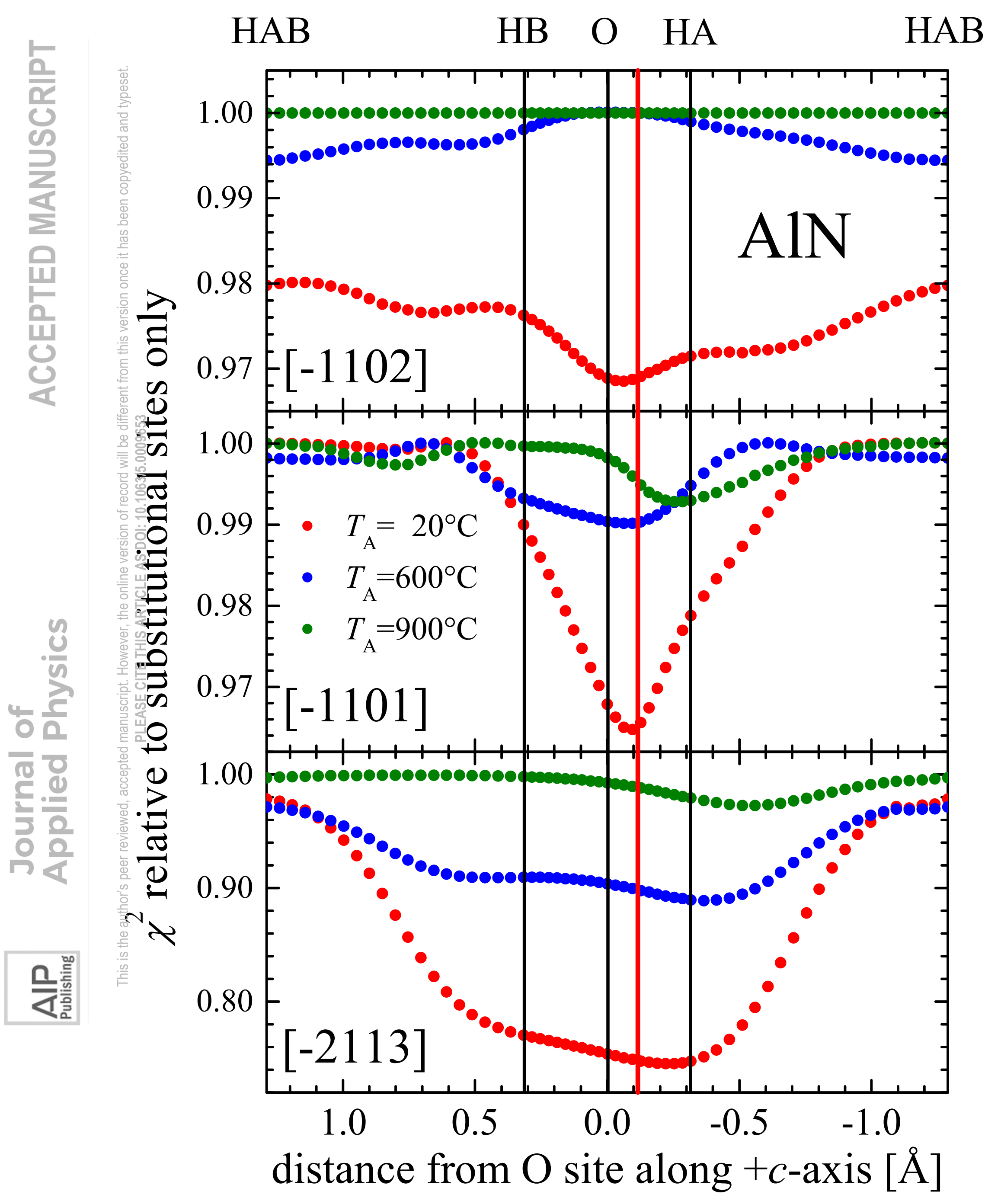




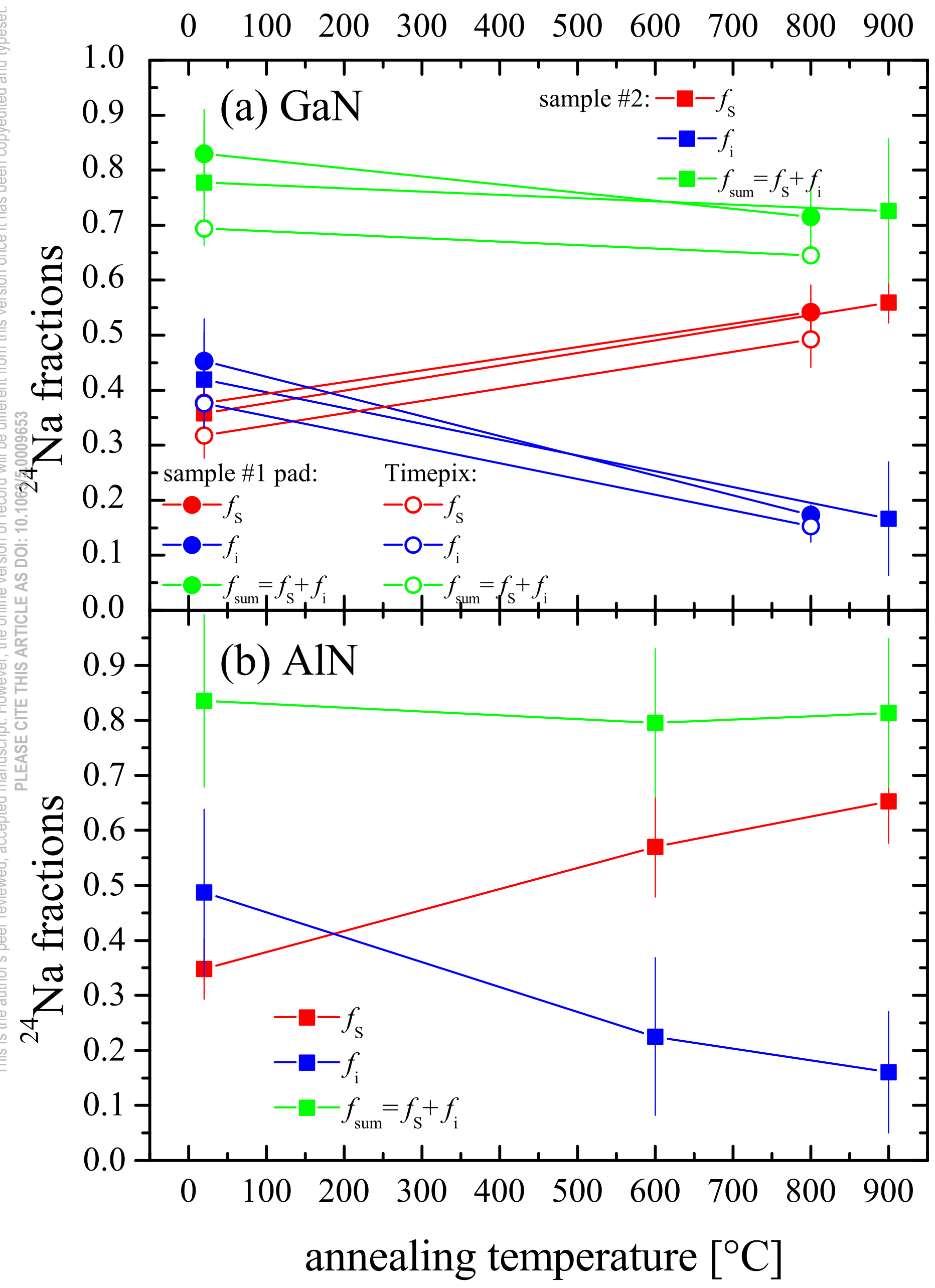

